\title{
AN IDEALIZED TRANSIENT MODEL FOR MELT DISPERSAL FROM REACTOR CAVITIES DURING PRESSURIZED MELT EJECTION ACCIDENT SCENARIOS
}

\author{
Narinder K. Tutu
}

June 1991

\section{DEPARTMENT OF NUCLEAR ENERGY}

BROOKHAVEN NATIONAL LABORATORY

ASSOCIATED UNIVERSITIES, INC.

UPTON, LONG ISLAND, NEW YORK 11973

UNDER CONTRACT NO. DE-AC02-76CHOOO16 WITH THE

UNITED STATES DEPARTMENT OFENERGY

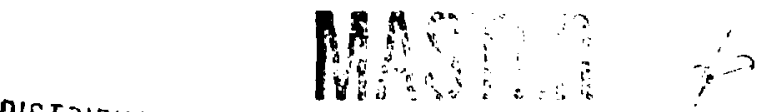




\begin{abstract}
The Direct Containment Heating (DCH) calculations require that the transient rate at which the melt is ejected from the reactor cavity during hypothetical pressurized melt ejection accident scenarios be calculoted. However, at present no models, that are able to predict the available melt dispersal data from small scale reactor cavity models, are available. In this report, a simple idealized model of the melt dispersal process within a reactor cavity during a pressurized melt ejection accident scenario is presented. The predictions from the model agree reasonably well with the integral data obtained from the melt dispersal experiments using a small scale model of the Surry reactor cavity.
\end{abstract}




\section{TABLE OF CONTENTS}

Page

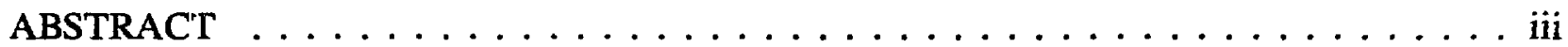

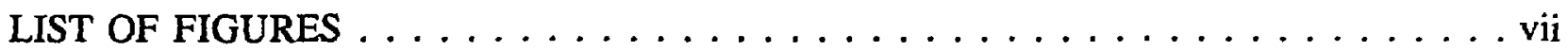

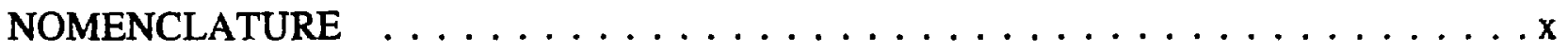

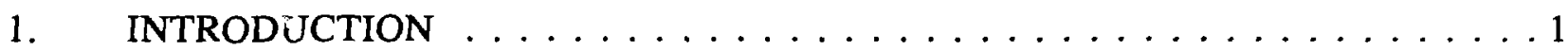

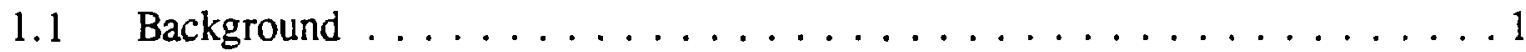

1.2 An Overview of Small Scale Reactor Cavity Melt Dispersal Experiments . . 2

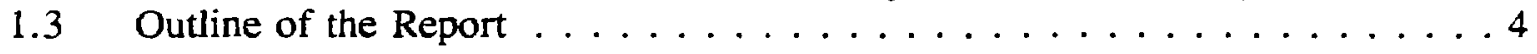

2. AN IDEALIZED QUASI-STEADY MELT DISPERSAL MODEL . . . . . . . 5

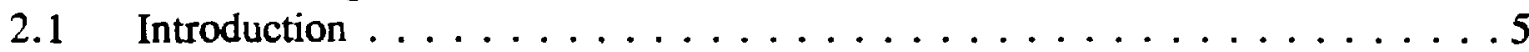

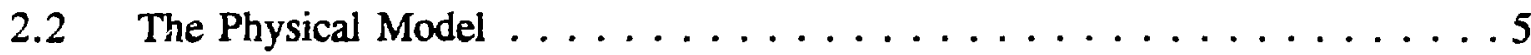

2.3 Modeling of the Equilibrium Entrained Fraction of Liquid Flux, $\mathrm{E}_{\infty} \ldots \ldots$

2.4 Procedure for Predicting the Transient Melt Dispersal Rate . . . . . . . . 11

3. MELT DISPERSAL PREDICTIONS FOR THE SURRY CAVITY _. . . . . . . 17

3.1 Comparison of Predictions and Experimental Data from $1 / 42^{\text {nd }}$ Scale

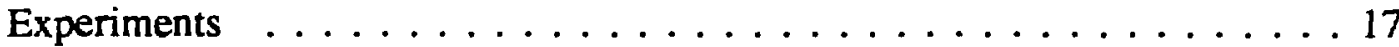

3.2 Predictions for the Full Scale Surry Cavity . . . . . . . . . . . 23

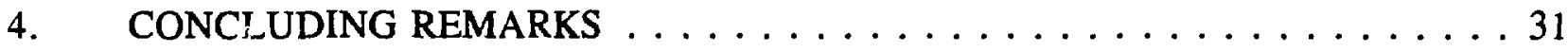

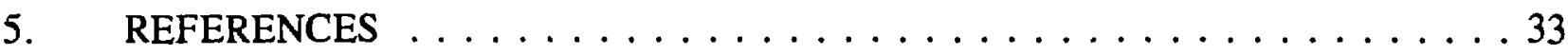




\section{LIST OF FIGURES}

Figure

Page

Schematic of the observed gas flow field within the $1 / 42^{\text {nd }}$ scale Surry cavity model. All dimensions are in $\mathrm{mm} . \mathrm{A}_{\mathrm{ww}}=0.1198 \mathrm{~m}^{2} \ldots \ldots .3$

A schematic of the idealized melt and gas flow within the Surry cavity $\ldots 6$

Definition sketch of the "equivalent" one dimensional duct $\ldots \ldots \ldots \ldots$

Predictions for the equilibrium entrainment fraction $\left(E_{\infty}\right)$ from

Equation (13) with $C=8.64$, plotted against the experimental data of Cousins and Hewitt $[15] \ldots \ldots \ldots \ldots \ldots \ldots \ldots \ldots$

Predictions of the equilibrium entrainment fraction $\left(E_{\infty}\right)$ from the Ishii \& Mishima model, Equation (10), plotted against the experimental data of Cousins and Hewitt [15]

Predictions from the present model, and the experimental data of Tutu et al. [7], for the fraction of melt retained within the Surry cavity model at the end of the gas blowdown ( $\left.f_{\text {end }}\right)$. $\mathrm{Vm}(0)=1.903 \times 10^{-4} \mathrm{~m}^{3} \ldots \ldots \ldots \ldots \ldots \ldots$

Predictions from the present model, and the experimental data of Tutu et al. [7], for the fraction of melt retained within the Surry cavity model at the end of the gas blowdown ( $f_{\text {end }}$ ).

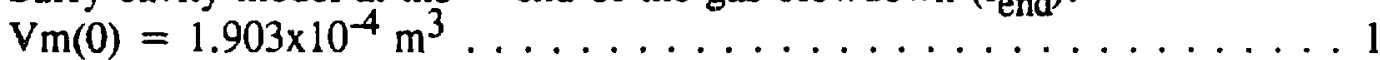

Predictions from the present model, and the experimental data of Tutu et ai. [7], for the fraction of melt retained within the Surry cavity model at the end of the gas blowdown ( $\left.f_{\text {end }}\right)$.

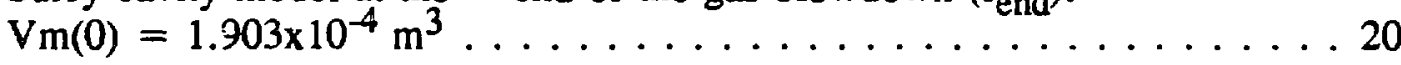

9 Predictions from the present mudel, and the experimental data of Tutu et al. [7], for the fraction of melt retained within the Surry cavity model at the end of the gas blowdown $\left(\mathrm{f}_{\text {end }}\right)$.

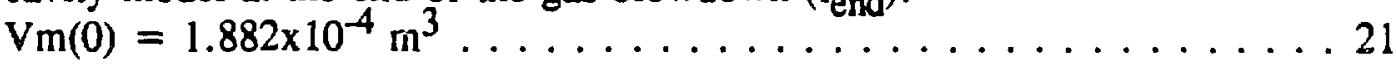

10 Predictions of the vessel pressure $\operatorname{Pv}(t)$, and the fraction of melt dispersed from the $1 / 42^{\text {nd }}$ scale Surry cavity model in the time interval zero to $t$, as a function of time. $\mathrm{P}_{\mathrm{o}}=\mathrm{Pv}(0)=4.4 \mathrm{MPa} \ldots \ldots 22$ 
LIST OF FIGURES (continued)

Figure

11 Comparisons of predictions for $f_{\text {end }}$ obtained from the present model, and those obtained from the empirical dimensionless correlation developed by Tutu et al. [7], for the full scale Surry cavity.

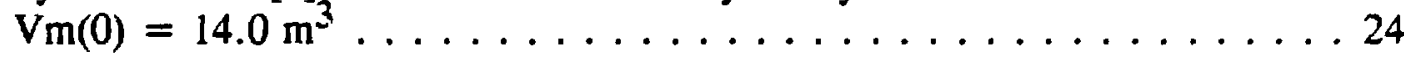

12 Comparison of predictions for $\mathrm{f}_{\text {end }}$ obtained from the present model, and those obtained from the empirical dimensionless correlation developed by Tutu et al. [7], for the full scale Surry cavity.

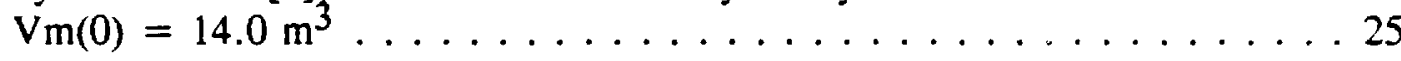

13 Predictions of the vessel pressure $P v(t)$, and the fraction of melt dispersal from the full scale Surry cavity in the time interval zero to $t$, as a function of time. $P_{0}=\operatorname{Pv}(0)=7.5 \mathrm{MPa} \ldots \ldots 26$

14 Predictions of the vessel pressure Pv(t), and the fraction of melt dispersed from the full scale Surry cavity in the time interval zero to $t$, as a function of time. $\mathrm{P}_{0}=\mathrm{Pv}(0)=4.0 \mathrm{MPa} \ldots \ldots \ldots 27$

Predictions of the vessel pressure $\operatorname{Pv}(\mathrm{t})$, and the fraction of melt dispersed from the full scale Surry cavity in the time interval zero to $t$, as a function of time. $\mathrm{P}_{\mathrm{o}}=\mathrm{Pv}(0)=1.75 \mathrm{MPa} \ldots \ldots \ldots 28$ 


\section{NOMENCLATURE}

A Area of cross-section of the "equivalent" one dimensional (1D) duct, $=\mathbf{P} \delta$.

$\mathrm{A}_{\mathrm{e}} \quad$ Cavity exit area for the actual three dimensional (3D) cavity (see Figure 2).

$A_{\min }$ Minimum of $\mathrm{A}$ or $\mathrm{A}_{\mathrm{e}}$.

$A_{w w}$ Total surface area of all the walls, excluding the roof, for the actual 3D cavity.

C A constant, dependent upon the cavity geometry, in the correlation for E.

$C_{D}$ Discharge coefficient for sonic flow through a circular orifice.

$\mathrm{d}_{0}$ Diameter of the hole in the pressure vessel through which the melt and the gas are discharged into the reactor cavity.

D Hydraulic diameter of the equivalent 1D duct, $=4 \delta$.

$\mathrm{D}_{\mathrm{c}} \quad$ Hydraulic diameter of the actual 3D cavity near the cavity exit (Region 1 in Figure 2).

D* Dimensionless value for $D$ as given by Equation (14)

E Fraction of liquid flux flowing as droplets, $=\mathrm{j}_{\mathrm{fe}} / \mathrm{j}_{\mathrm{f}}$.

$E_{\infty} \quad$ Equilibrium value of $E$

$\mathrm{f}, \mathrm{f}(\mathrm{t})$ Fraction of initial melt volume remaining within the cavity at any time $t$.

$f_{\text {end }} \quad$ Value of $f$ at the end of the gas blowdown.

g Acceleration due to gravity.

$\mathrm{j}_{\mathrm{f}} \quad$ Superficial velocity of total liquid (melt) in the equivalent 1D duct.

$\mathrm{j}_{\mathrm{fe}} \quad$ Superficial velocity of entrained droplets in the equivalent $1 \mathrm{D}$ duct.

$\mathrm{j}_{\mathrm{ff}} \quad$ Superficial velocity of liquid film in the equivalent 1D duct.

$\mathrm{j}_{\mathrm{g}} \quad$ Superficial velocity of gas in the equivalent 1D duct.

$\mathrm{Ku}_{\mathrm{g}} \quad$ See Equation (15).

$\mathrm{Ku}_{\mathrm{f}} \quad$ See Equation (16).

$\mathrm{L}_{\mathrm{eq}} \quad$ Length of the equivalent $1 \mathrm{D}$ duct.

$\mathrm{m} \quad$ Average melt film thickness at any time $t$.

$m_{g}(t)$ Mass flow rate of gas through the pressure vessel at any time $t$.

$\mathrm{m}_{\mathrm{g}}^{0} \quad$ Mass flow rate of gas through the pressure vessel at $\mathrm{t}=0$.

$\mathbf{M}_{0} \quad$ Initial mass of gas in the pressure vessel.

$\mathrm{N}_{\mu}:$

$$
N_{\mu}=\frac{\mu_{f}}{\left(\rho_{f} \sigma \sqrt{\frac{\sigma}{g \Delta \rho}}\right]^{0.5}}
$$

P Perimeter of the cavity walls assumed to be wetted by the liquid film near the cavity exit. 
For the Surry cavity model shown in Figure 2 , it equals $(w+2 h)$. It is also the perimeter of the equivalent ID cavity.

$\mathrm{P}_{0} \quad$ Initial pressure in the pressure vessel, $=\mathrm{Pv}(0)$.

$P v(t)$ Pressure in the pressure vessel at any time $t$.

R "Particular" gas constant for the gas in the p.essure vessel.

$t \quad$ Time in seconds.

$\mathrm{T}_{0} \quad$ Initial temperature of the gas in the pressure vessel.

$\mathrm{T}_{0}^{\prime} \quad$ Assumed temperature of steam within the cavity for the full scale case.

$u_{g} \quad$ Velocity of the gas phase in the equivalent 1D duct.

$\mathrm{u}_{\mathrm{fe}} \quad$ Velocity of the entrained droplets in the equivalent $1 \mathrm{D}$ duct.

$\mathrm{V}_{0} \quad$ Volume of the pressure vessel

$\mathrm{V}_{\mathrm{e}} \quad$ Total volume of entrained droplets within the equivalent ID duct at any time $t$.

$\mathrm{V}_{\mathrm{eq}}$ Volume of equivalent $1 \mathrm{D}$ cavity, $=\mathrm{AL}_{\mathrm{eq}}$.

$V m(t)$ Total volume of melt within the cavity at any time $t$.

\section{Greek Letters}

$\alpha_{\mathrm{fe}} \quad$ Volume fraction of liquid droplets.

$\gamma \quad$ Ratio of specific heat at constant pressure to specific heat at constant volume for the gas.

$\delta \quad$ Assumed width of the gas flow region in the actual 3D cavity as given by Equation (17).

$\eta \quad$ See Equation (10).

$\mu_{\mathrm{f}} \quad$ Absolute viscosity of the liquid phase.

$\rho_{\mathrm{g}} \quad$ Density of the gas phase.

$\rho_{\mathrm{f}} \quad$ Density of the liquid phase.

$\Delta \rho \quad=\left(\rho_{\mathrm{f}}-\rho_{\mathrm{g}}\right)$

$\sigma \quad$ Surface tension of the liquid-gas pair. 


\section{INTRODUCTION}

\subsection{Background}

Consider a potential core melt accident sequence during which the nuclear reactor pressure vessel fails while the primary system is still pressurized. Prior to vessel failure,the molten core material is assumed to exist as a molten pool at the vessel bottom. Since the pressure within the primary system in this scenario is assumed to be much larger than the pressure in the containment, upon vessel failure the melt would be driven from the reactor pressure vessel into the region directly beneath the vessel. The region directly underneath the pressure vessel is termed as the "reactor cavity". Depending upon the melt volume, the hole size in the vessel bottom, and the initial pressure in the primary system at the time of vessel failure, at some instant, steam would "punch a hole" through the pool of core melt at the vessel bottom, and flow into the reactor cavity region [1,2] along with the melt. Following the completion of the two-phase melt-steam discharge, steam from the primary system would continue to blow down from the primary system into the reactor cavity until the pressures in the primary system and the reactor cavity are equilibrated. Steam, which is calculated to move at a high velocity through the reactor cavity, is fostulated to fragment the molten core material (oxides and unreacted Zirconium and stainless steel) into droplets, interact thermally and chemically (thus producing hydrogen) with the melt, and carry some fraction of melt mass into the containment subcompartments just above the cavity. The core debris exiting the reactor cavity is again available to interact thermally and chemically with the atmosphere (steam and air) of the containment building. Hydrogen produced in the reactor cavity and the containment subcompartments will be transported to the containment dome where combustion with oxygen would occur if conditions permit. This phenomenon of direct energy exchange between the core melt and the containment atmosphere (via melt-atmosphere heat transfer, melt-steam chemical reaction, melt-oxygen chemical reaction, and hydrogen combustion), which leads to rapid heating of the containment atmosphere, and hence rapid pressurization, is termed direct containment heating $(\mathrm{DCH})$. For a detailed discussion of the DCH phenomena, the reader is referred to References [2] and [3].

The DCH accident scenario which is outlined above, and which is a consequence of the "pressurized melt ejection accident scenario", involves interactions in three regions of the containment building: (i) the reactor cavity, (ii) the containment subcompartments between the reactor cavity and the containment dome, and (iii) the containment dome. Since the extent of direct energy exchange between the melt and the containment atmosphere is proportional to the interfacial area between the two phases (melt and gas) and the efficiency of mixing between the two phases, it follows that to a first order only the fraction of core melt that is entrained as droplets by the gas phase would contribute to the $\mathrm{DCH}$ pressure loading. The amount of core melt that is ejected from the reactor cavity indicates that at least that much melt was entrained within the cavity ${ }^{1}$ and had an opportunity to intemat thermally and chemically with the steam flowing through the cavity. In addition, the amount of melt leaving the reactor cavity is free

${ }^{1}$ For some special cavity shapes, like Zion for example, some melt can exit the cavity under its own momentum as a film even without entrainment. 
to interact with the containment atmosphere downstream of the reactor cavity region until it is trapped by the containment structures downstream of the cavity. Therefore, the mass flow of core debris exiting the reactor cavity has a strong influence on the $\mathrm{DCH}$ loading. A model that would predict the transient melt dispersal rate from a reactor cavity during a pressurized melt ejection accident scenario is therefore needed, and is the subject of this paper. At present, the NRC CONTAIN code $[4,5]$ is being used to predict the loading due to DCH. However, CONTAIN is not a detailed multiphase fluid dynamics code and cannot predict the extent of melt entrainment (or dispersal) from the reactor cavity. In fact, the user must supply this information as an input to the code. Thus the transient melt dispersal model, which is the subject of this paper, could be directly used for CONTAIN DCH calculations.

\subsection{An Overview of Small Scale Reactor Cavity Melt Dispersal Experiments}

To study the melt dispersal characteristics of reactor cavities, Tutu et al $[3,6,7]$ have performed simulant melt dispersal experiments with the $1 / 42^{\text {nd }}$ scale models of the Zion, the Surry, and the Watts Bar reactor cavities. In these experiments, water and molten Wood's metal were used as the melt simulants. Each experiment yielded the data for $f_{\text {end }}$, the fraction of melt simulant that remained within the cavity model at the end of the gas blowdown from the pressure vessel. Thus these were integral tests, and no transient measurements of the melt flow rate exiting the reactor cavity model were made. Numerous experiments for various initial conditions, namely: $\mathrm{P}_{0}$, the initial pressure in the pressure vessel and $\mathrm{d}_{0}$, the diameter of the hole through which the melt simulant and the gas are discharged into the cavity, were performed. In addition, the experimental parameters included: melt simulant (water or molten Wood's metal) and the driver gas (nitrogen or helium). Tutu et al [6] also performed a scaling analysis of the melt dispersal process and obtained a list of dimensionless groups relevant to the melt dispersal phenomena. Tutu et al $[3,7]$ have used these scaling groups to successfully obtain a dimensionless correlation for $f_{e n d}$ for each of the three cavities they studied.

Melt dispersal experiments using small scale models of reactor cavities have also been performed by Spencer et al [8, 9], Tarbell et al [10, 11], Macbeth and Trenberth [12], and Hall and Dawson [13]. An important experimental result obtained by Macbeth and Trenberth [12], who made gas velocity measurements within the cavity model, was that the gas velocity is highly nonuniform in the cavity. Their measurements showed that the gas velocity near the floor and vertical side walls of the cavity could be five to eight times the average gas velocity. Tutu et al [6], who shot high speed motion pictures of selected experiments to study the cavity dispersal phenomena, also report highly nonuniform and turbulent flow field within the cavity. Figure 1 shows a schematic of the observed gas flow field within the Surry cavity model. In this figure $B$ is the orifice through which the melt simulant is discharged into the cavity model and C,D are the cavity exits. During the melt discharge phase of the transient, when only the melt simulant is being ejected from the orifice B, the melt is observed to spread along the floor of the cavity and climb the vertical walls of the cavity. During this process some splashing and consequent droplet production is also observed. But by and large, by the end of the melt discharge phase the cavity floor and most of the vertical walls of the cavity are observed to be covered with the melt simulant. Following the discharge of melt simulant, the driver gas discharges from the pressure vessel through $B$ into the cavity. The gas jet upon impinging the floor of the cavity 
NOTE: All dimensions are in $\mathrm{mm}$

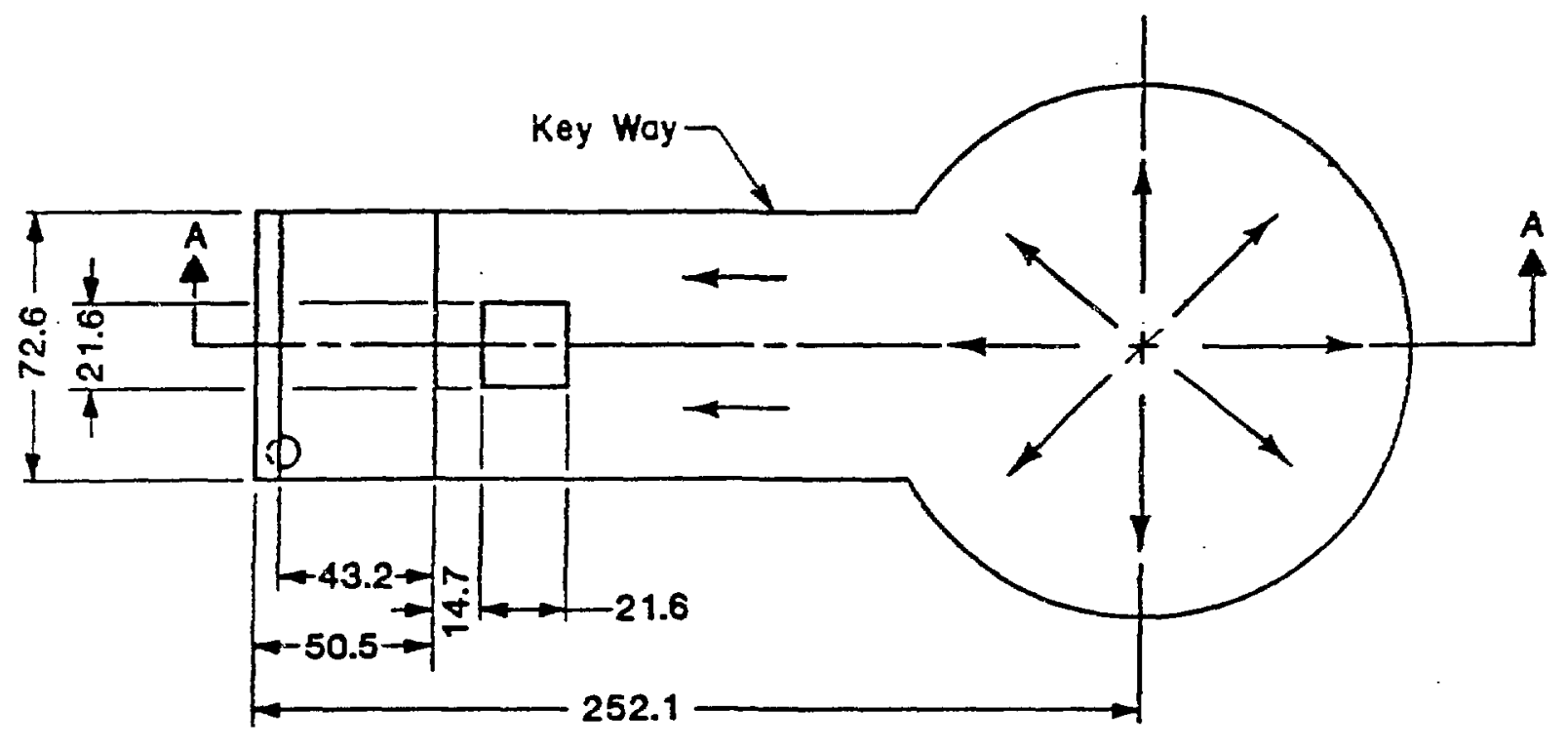

PLAN VIEW

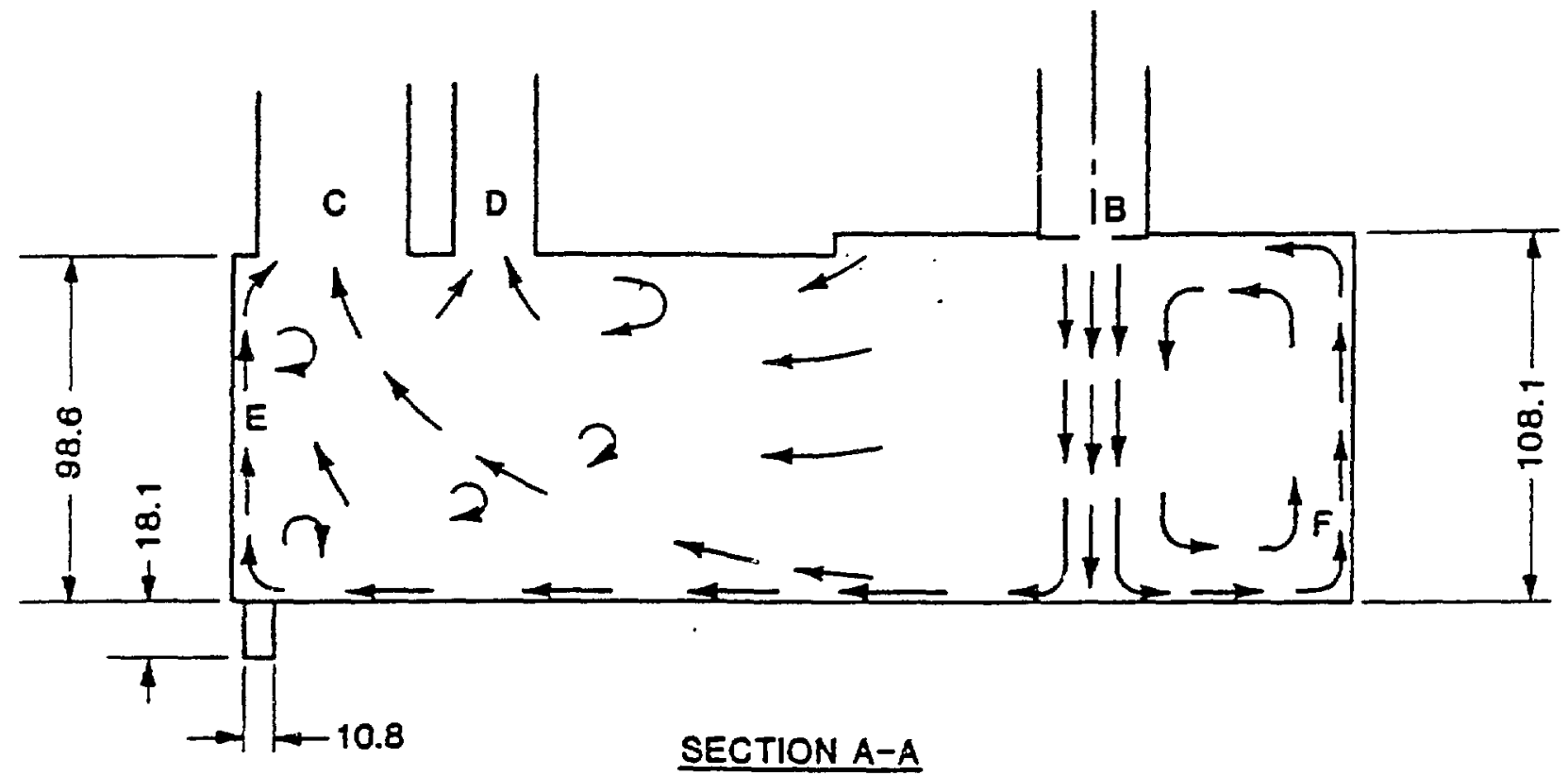

Figure 1. Schematic of the observed gas flow field within the $1 / 42^{\text {nd }}$ scale Surry cavity model. All dimensions are in $\mathrm{mm}$. $\mathrm{A}_{\mathrm{ww}}=0.1198 \mathrm{~m}^{2}$. 
travels radially outward. While part of the gas flow continues to travel downstream, the remaining flow is observed to recirculate within the cylindrical portion (F) of the cavity. The flow was observed to be highly turbulent and nonuniform. Small regions of flow reversal were observed intermittently near the roof of the "key way" in the cavity. The flowing gas is observed to quickly entrain melt from films along the walls, and carry these entrained droplet: out of the cavity model through exits $\mathrm{C}$ and $\mathrm{D}$.

\subsection{Outline of the Report}

The debris dispersal process is a highly transient and complicated hydrodynamic phenomenon involving simultaneous droplet entrainment and droplet deposition on the walls of the cavity. In the real full scale case the composition and the temperature of the gas phase within the cavity are further influenced by the melt-steam heat transfer and the milt-steam chemical reaction. However, the melt dispersal process is essentially hydrodynamic in nature. In this report therefore, for the purpose of developing a basic melt dispersal model, we shall restrict ourselves to an isothermal case with no chemical interaction between the gas phase and the melt. In the next section we shall present a highly idealized transient model for melt dispersal. The objective of the model is to provide us with a method that would enable us to calculate approximately the mass flow rate of melt leaving the cavity as a function of time during the transient. Then, in Section 3, in order to judge the adequacy of the model, we shall compare the predictions from this model for $\mathrm{f}_{\text {end }}$ to the experimental data for $\mathrm{f}_{\text {end }}$ obtained with the $1 / 42^{\text {nd }}$ scale Surry cavity model. Finally, in Section 4 we shall present some concluding remarks. 


\subsection{Introduction}

As discussed above, the melt dispersal process in a reactor cavity is an highly complex three dimensional transient phenomenon. A rigorous treatment of it would involve the development of a 3D transient multiphase code in which the liquid field is further subdivided into a droplet field and a film field. This task is further complicated by the necessity to provide constitutive relationships for entrainment, deposition, droplet collisions, and turbulence modeling in regimes for which no basic experimental data are available. Such a task is clearly beyond the scope of the present work. However, as discussed in Section 1.1, in order to perform CONTAIN-DCH calculations one must simply "guess" the transient mass flow rate of melt entrained within the cavity and piovide it as an input to the code. This is clearly unsatisfactory. As a first step towards resolution of this problem, therefore, the objective of the present paper is to develop a simple model that provides a first approximation to the melt dispersal rate, and yet captures the essential mechanics of the melt dispersal process.

\subsection{The Physical Model}

Since the hydrodynamic processes in the actual 3D cavity are too complex to be solved directly, we use the following approach. Based upon the experimental evidence $[6,12]$, we hypothesize some essential features of the melt dispersal process and then "transform" the actual 3D cavity into an "equivalent" 1D cavity (or duct). We further assume the flow of droplets, film, and the gas to be in a state of "quasi-equilibrium" near the exit of this equivalent ID duct. This simplified problem is then solved more easily.

As discussed in Section 1.2 and observed by Tutu et al. [6], just before the onset of gas blow down from the pressure vessel, the melt is observed to be spread along the floor and vertical walls of the cavity. Therefore, as shown in Figure 2, we shall assume the melt to be distributed along all the walls of the cavity except the roof. Let this surface area of the cavity walls except the roof be denoted by $A_{w w}$. Furthermore, since the experimental measurements of Macbeth and Trenberth [12] show that the gas velocities near the floor and the vertical walls of the cavity are five to eight times the average gas velocity within the cavity, we further assume that the gas flow is restricted to a region $\delta$ along the floor and vertical walls of the cavity. This is indicated in Figure 2. The modeling of $\delta$ would be discussed in Section 2.4. This figure also shows that we divide the cavity into two regions. In Region 1 , which is directly adjacent to the cavity exits, the bulk gas flow is predominantly in the direction of cavity exits. On the other hand, in Region 2, which is the cylindrical portion of the cavity directly underneath the reactor pressure vessel, the bulk flow has a large recirculating zone.

Let $\mathrm{P}$ be the perimeter of the cavity walls wetted by the melt film in Region 1 of the cavity. For the Surry cavity model shown in Figure 2 , it equals $(v+2 h)$ since we assume that no melt film exists on the roof of the cavity. Note that if $\delta$ is assumed to be much smaller than the cavity width and height, the cavity cross-sectional area in Region 1, through which the bulk gas flow is assumed to occur, is equal to $\mathrm{P} \delta$. As shown in Figure 3, we now define an 


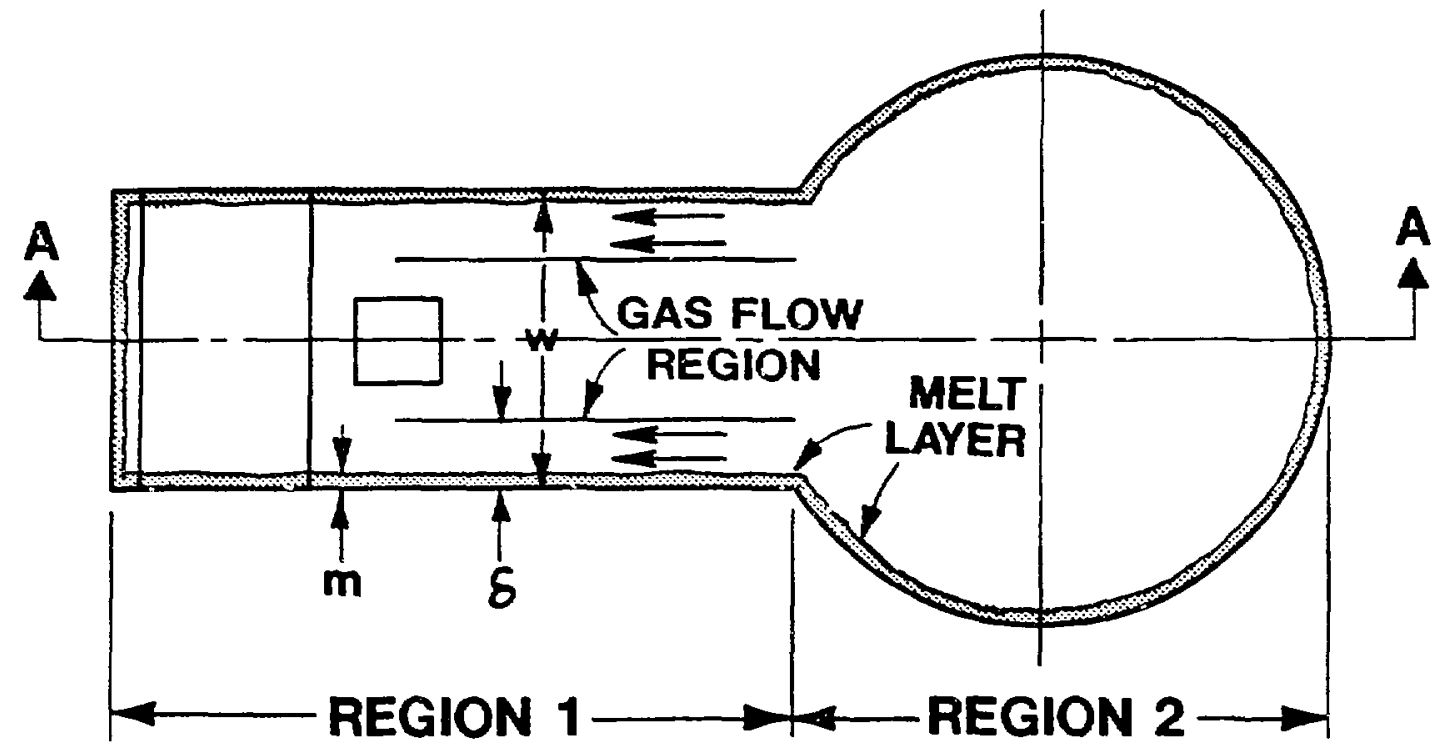

PLAN VIEW

Ae, CAVITY

EXIT AREA

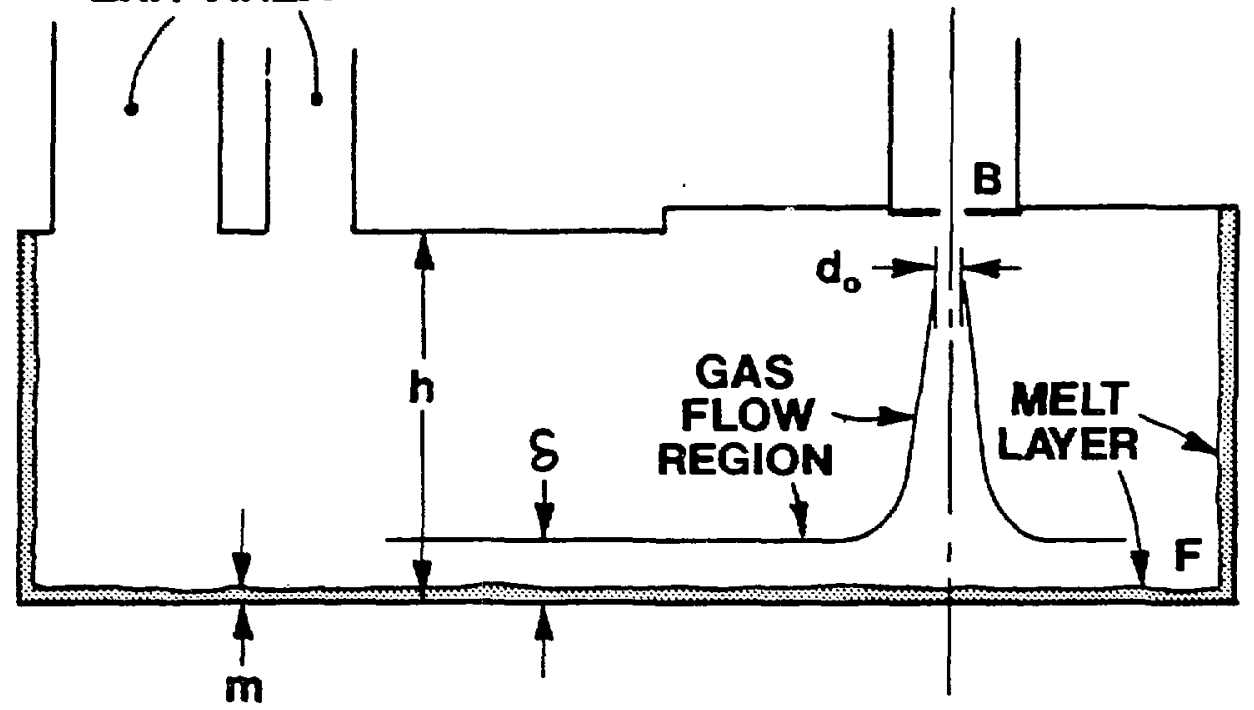

SECTION A-A

Figure 2. A Schematic of the idealized melt and gas flow within the Surry cavity. 


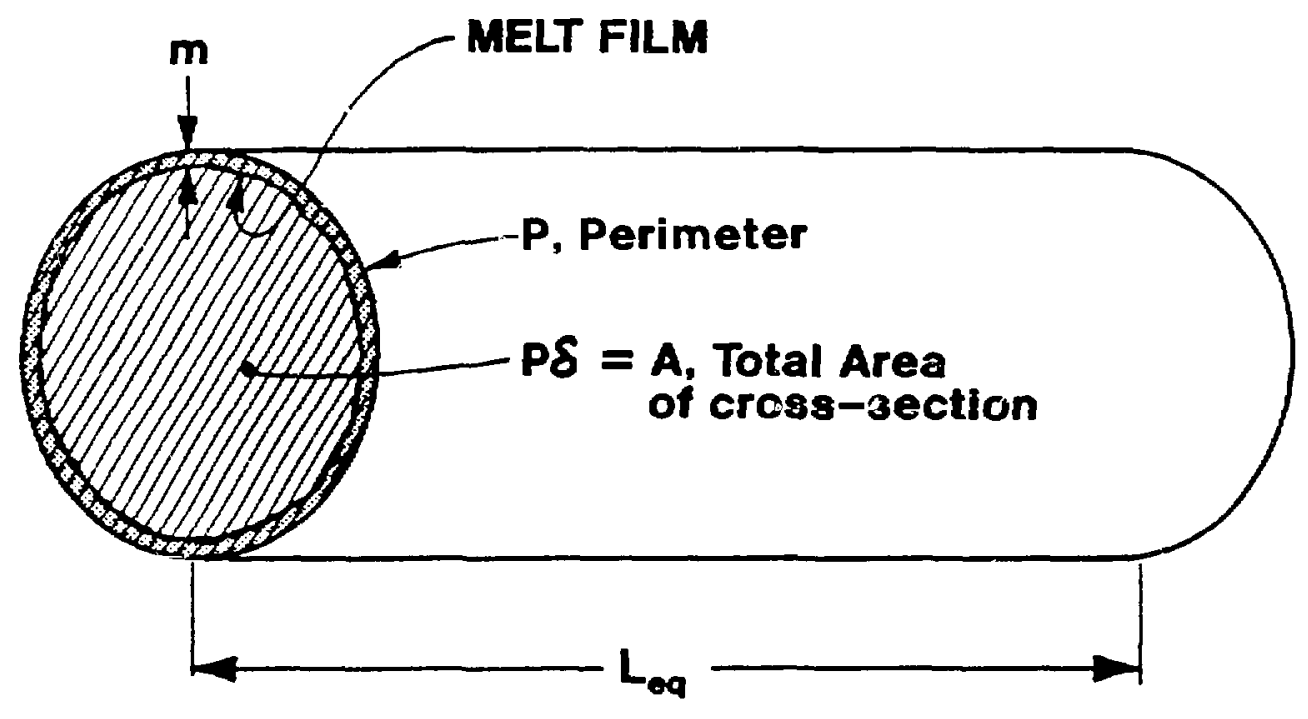

Figure 3. Definition Sketch of the "equivalent" one dimensional duct. 
"equivalent" one dimensional duct that would serve as an analogue for the actual 3D cavity for calculational purposes. The cross-sectional shape of this duct is such that it also has a perimeter of $\mathrm{P}$, and a cross-sectional area of $\mathrm{P} \delta$. Therefore, the hydraulic diameter $\mathrm{D}$ of this duct is equal to $4 \delta$. Furthermore, the length $\mathrm{L}_{\mathrm{eq}}$ of this $1 \mathrm{D}$ duct is chosen such that it would have a total wall surface area that is the same as the wall surface area assumed to be occupied by the melt film in the actual 3D cavity. Let $A$ be the cross-sectional area, $j_{f e}$ the superficial velocity of the droplets, $j_{f}$ the total superficial velocity of the melt, $j_{\mathrm{ff}}$ the superficial velocity of the melt film, and $E$ the fraction of melt flux flowing as droplets in the equivalent one dimensional duct, then:

$$
\begin{gathered}
A=P \delta \\
\mathrm{L}_{\mathrm{eq}}=\mathrm{A}_{\mathrm{ww}} / \mathrm{P} \\
\mathrm{E}=\mathrm{j}_{\mathrm{fe}} / \mathrm{j}_{\mathrm{f}} \\
\mathrm{j}_{\mathrm{f}}=\mathrm{j}_{\mathrm{ff}}+\mathrm{j}_{\mathrm{fe}}=\mathrm{j}_{\mathrm{ff}}+E \mathrm{j}_{\mathrm{f}}
\end{gathered}
$$

We shall now find approximate relationships for the fraction of volume occupied by the liquid (melt) droplets, $\alpha_{\mathrm{fe}}$ and the superficial velocity of the melt film. $j_{\mathrm{ff}}$. Since the void fraction of the gas phase for this problem is reasonably close to unity, we shall therefore, for the purposes of modeling $\alpha_{\mathrm{fe}}$ and $\mathrm{j}_{\mathrm{ff}}$, assume that the gas velocity $u_{\mathrm{g}}$ is approximately equal to the superficial velocity of the gas phase, $\mathrm{j}_{\mathrm{g}}$. Furthermore, we shall assume that the droplet slip is equal to $1 / 2$, that is, the droplet velocity $u_{\mathrm{fe}}$ is equal to half the gas velocity). Therefore,

$$
\mathrm{j}_{\mathrm{fe}}=\alpha_{\mathrm{fe}} \mathrm{u}_{\mathrm{fe}}=\alpha_{\mathrm{fe}} \mathrm{u}_{\mathrm{g}} / 2 \approx \alpha_{\mathrm{fe}} \mathrm{j}_{\mathrm{g}} / 2
$$

Substituting Equation (3) in the above relation, we get:

$$
\alpha_{\mathrm{fe}}=2 \mathrm{E} \mathrm{j} / \mathrm{j}_{\mathrm{g}}
$$

To calculate the melt film superficial velocity, we shall assume that the melt film-gas interface is moving with the gas velocity, and that the velocity profile in the melt film is linear. Thus, the volume flow raic of melt film is given by:

$$
P m j_{g} / 2=A j_{f f}=P \delta j_{f f}
$$

Therefore,

$$
\mathrm{j}_{\mathrm{ff}}=\mathrm{m} \mathrm{j}_{\mathrm{g}} /(2 \delta)
$$

Let $\mathrm{V}_{\mathrm{e}}$ be the total volume of entrained melt droplets in the ID duct at any time $t$, then:

$$
\mathrm{V}_{\mathrm{e}}=\alpha_{\mathrm{fe}} A \mathrm{~L}_{\mathrm{eq}}=2 \mathrm{E}\left(\mathrm{j}_{\mathrm{f}} / \mathrm{j}_{\mathrm{g}}\right) A \mathrm{~L}_{\mathrm{eq}}
$$

If $\mathrm{Vm}$ is the total volume of melt at any time $\mathrm{t}$ within the $1 \mathrm{D}$ duct, then, the instantaneous melt film thickness $m$ is given by: 


$$
m=\left(V m-V_{e}\right) / A_{w w}
$$

The volume of the equivalent cavity (1D duct), $\mathrm{V}_{\text {eq }}$ is given by:

$$
\mathrm{V}_{\mathrm{eq}}=\mathrm{AL}_{\mathrm{eq}}=\mathrm{P} \delta \mathrm{A}_{\mathrm{ww}} / \mathrm{P}=\delta \mathrm{A}_{\mathrm{ww}}
$$

Using the above relation and equations (4),(6),(7), and (8), we get

$$
\mathrm{j}_{\mathrm{f}}=(1 / 2) \mathrm{j}_{\mathrm{g}}\left(\mathrm{Vm} / \mathrm{v}_{\mathrm{eq}}\right)
$$

In order to calculate the droplet flow rate exiting the reactor cavity as a function of time, we must compute $j_{\text {fe }}$, the droplet superficial velocity. Since $j_{f e}=E j_{f}$, we must next develop a model for $\mathrm{E}$. Here again, in spite of the fact that the flow is transient and decaying with time, we shall make the highly simplifying assumption that the flow of droplets, film, and the gas is in a state of "equilibrium" at every instant of time during the transient blowdown process. Therefore, we shall assume that a model developed for $E_{\infty}$, the equilibrium value of $E$, can be used in our case. The modeling of $E$ is discussed in the next section.

\subsection{Modeling of the Equilibrium Entrained Fraction of Liquid Flux, $E_{\infty}$}

For a fully developed one dimensional steady annular pipe flow, Ishii and Mishima [14] developed the following empirical correlation for $E_{\infty}$, the fraction of liquid flux flowing as droplets in the equilibrium region:

$$
E_{\infty}=\tanh \left(7.25 \times 10^{-7} \eta\right)=\tanh \left(7.25 \times 10^{-7} W^{1.25} \operatorname{Re}_{\mathrm{f}}^{0.25}\right)
$$

where,

$$
\begin{gathered}
W e=\frac{\rho_{g} j_{g}^{2} D}{\sigma}\left(\frac{\Delta \rho}{\rho_{g}}\right)^{1 / 3} \\
R e_{f}=\left(\frac{\rho_{f} j_{f} D}{\mu_{f}}\right)
\end{gathered}
$$

This correlation was obtained by assuming $\mathrm{E}_{\infty}$ to depend upon a product of certain powers of the following three dimensionless parameters: the total liquid Reynolds number, the dimensionless gas flux, and the dimensionless pipe diameter. Several points need to be noted regarding the direct applicability of this correlation for the present problem. First, the correlation was tested for experimental data obtained with water only. Therefore, in the experimental data base the liquid phase density, $\rho_{\mathrm{f}}$ and the surface tension, $\sigma$ were essentially constants. Thus the applicability of Equation (10) to fluids like molten corium and molten Wood's metal, both of which have much higher density and surface tension than water, is yet to be verified. By substituting Equations (11) and (12) in Equation (10), we note that the 
argument of tanh, $\eta$ is given by:

$$
\eta \sim \rho_{\mathrm{f}}^{2 / 3}
$$

Therefore, the Ishii and Mishima [14] correlation indicates that if all the experimental variables except the fluid density are held fixed, a heavier fluid will have a higher entrainment fraction. That this should always be the case does not seem plausible. Although the gravitational force on the liquid film may tend to increase the instability on the liquid film on the wall, and hence increase entrainment due to increased interfacial shear, the liquid inertia, and hence the liquid density, could also play a stabilizing role. In any case, the dependence of $E$ on the liquid density implicit in the Ishii and Mishima correlation, as indicated above, is directly in contradiction to the integral experimental data obtained from melt dispersal experiments $[3,6,7]$, which show that in order to entrain the same volume fraction of a heavier fluid (molten Wood's metal) much higher gas fluxes are required. Consequently, it is clear that if we were to use the Ishii and Mishima [14] correlation to predict the melt dispersal, the model would fail. Therefore, we shall next modify the Ishii and Mishima correlation and compare the predictions from this modified correlation and the original Ishii and Mishima correlation to the experimental data of Cousins and Hewitt [15].

Based upon the trends suggested by the experimental data $[7,15]$, we assume the following correlation:

$$
E_{\infty}=\tanh \left[C K u_{g}^{2} K u_{f}^{0.33}\left(\frac{\rho_{g}}{\Delta \rho}\right)^{1.4} D_{*}^{0.48}\left(1-\exp \left(-D_{*} / 8\right)\right)\right]
$$

where,

$$
\begin{gathered}
\mathrm{D}_{*}=\mathrm{D}\{\mathrm{g} \Delta \rho / \sigma\}^{0.5} \\
K u_{g}=\left[\frac{j_{g} \rho_{g}^{0.5}}{(\sigma g \Delta \rho)^{0.25}}\right] \\
K u_{f}=\left[\frac{j_{f} \rho_{f}^{0.5}}{(\sigma g \Delta \rho)^{0.25}}\right]
\end{gathered}
$$

and $\mathrm{C}$ is a constant to be determined. The dimensionless pipe diameter $D_{*}$ is the ratio of the pipe diameter to the Taylor wavelength $(\sigma /(\mathrm{g} \Delta \rho))^{0.5}$. In Equation (13), $\mathrm{Ku}$ is the Kutateladze 
number and $\mathrm{Ku}_{\mathrm{f}}$ is the dimensionless liquid flux. While Ishii and Mishima used the liquid Reynolds number as the dimensionless parameter involving the liquid superficial velocity $\mathrm{j}_{\mathrm{f}}$, we hypothesize that for the current problem of interest $\left(D_{*}>10\right.$, and $N_{\mu} \leq 0.1$ ) the entrainment characteristics are independent of the liquid phase viscosity. The viscosity number $\mathbf{N}_{\mu}$ is defined in the Nomenclature.

Cousins and Hewitt [15] have made measurements of the flow rate of entrained droplets during annular flow of air and water in long vertical tubes. Before using the proposed correlation for $E_{\infty}$, as given in Equation (13), for the prediction of melt dispersal from reactor cavities, let us now test this correlation and the original Ishii and Mishima correlation, as given in Equation (10), against the basic experimental data of Cousins and Hewitt. Figure 4 shows a plot of $E_{\infty}$ as predicted by the present model (with $C=8.64$ ) against the experimental data for $E_{\infty}$. The triangular symbols in this figure represent the 102 data points ( selected at random from the first 340 data points from Table 1 of Cousins and Hewitt [15] ) for experiments with a $3 / 8$ inch diameter tube. The square symbols correspond to the 24 data points for experiments with the 1-1/4 inch pipe. The straight line in this figure indicates perfect correlation. As can be seen, the agreement between the data and predictions is not unreasonable, especially for $D_{*}$ $=11.61$. A similar comparison of predictions from the Ishii and Mishima model (Equation (10)) and the experimental data is shown in Figure 5. This figure shows that the Ishii and Mishima model simply does an excellen job of predicting the data for $\mathrm{D}_{*}=3.49$. However, by comparison, the agreement with the data for $D_{*}=11.61$ is poor. This figure strongly suggests that there are perhaps two distinct regimes of entrainment: one for the case when $D_{*}$ is of the order of unity (say $\mathrm{D}_{*} \leq 5$ ) and the other for which $\mathrm{D}_{*}$ is much larger than unity (say $D_{*} \geq 10$ ). It, therefore, appears that the Ishii and Mishima correlation may be best suited for cases when $D_{*} \leq 5$. A comparison of Figures 4 and 5 shows that the present correlation does a slightly better job of predicting the data for $D_{*}=11.61$ than the Ishii and Mishima correlation. Since the value of $D_{*}$ for the BNL debiis dispersal experiments [7] and the full scale Surry is caiculated to be larger than 10, the choice of the present correlation for $\mathrm{E}_{\infty}$ seems reasonable. In any case, as discussed earlier, the Ishii and Mishima correlation does not appear to have the proper dependence of $\rho_{f}$ upon $\mathrm{E}_{\infty}$.

\subsection{Procedure for Predicting the Transient Melt Dispersal Rate}

As discussed in Section 2.2, for calculational purposes we must first transform the actual 3D cavity into an "equivalent" $1 \mathrm{D}$ duct. Let $\mathrm{D}_{\mathrm{c}}$ be the actual hydraulic diameter of the cavity in Region 1. For example, for the Surry cavity model shown in Figure $2, D_{c}=(4 w h /(2 w+$ $2 \mathrm{~h})$ ). Again, based upon the experimental data [3,7], which suggests that the width of the gas flow region is related to the diameter of the orifice in the pressure vessel through which the gas is discharged $\left(\mathrm{d}_{0}\right)$, we hypothesize the following model for the gas flow width $\delta$ : 


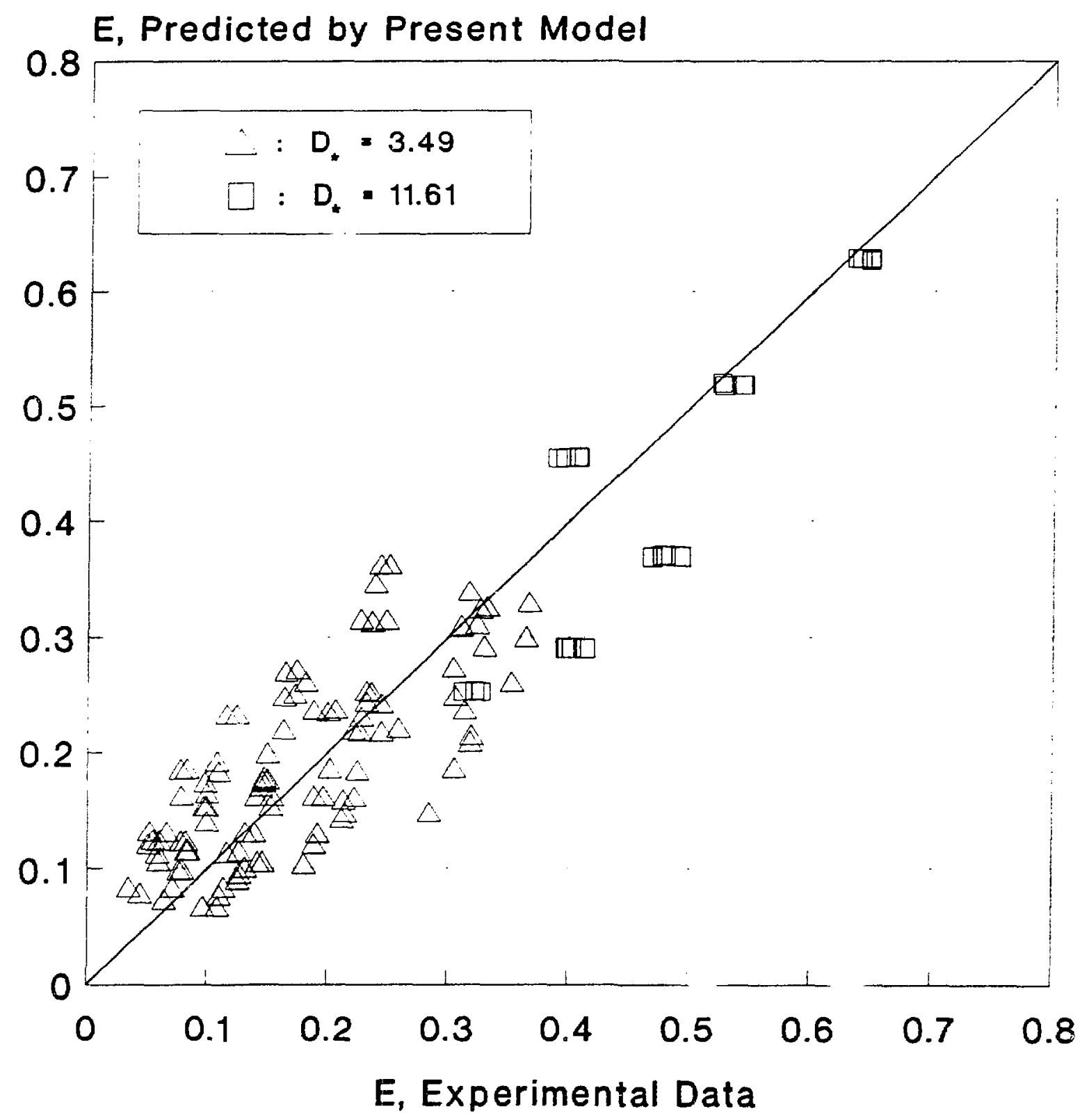

Figure 4. Predictions for the equilibrium entrainment fraction $\left(E_{\infty}\right)$ from Equation (13) wiin $\mathrm{C}=8.64$, plotted against the experimental data of Cousins and Hewitt [15]. 


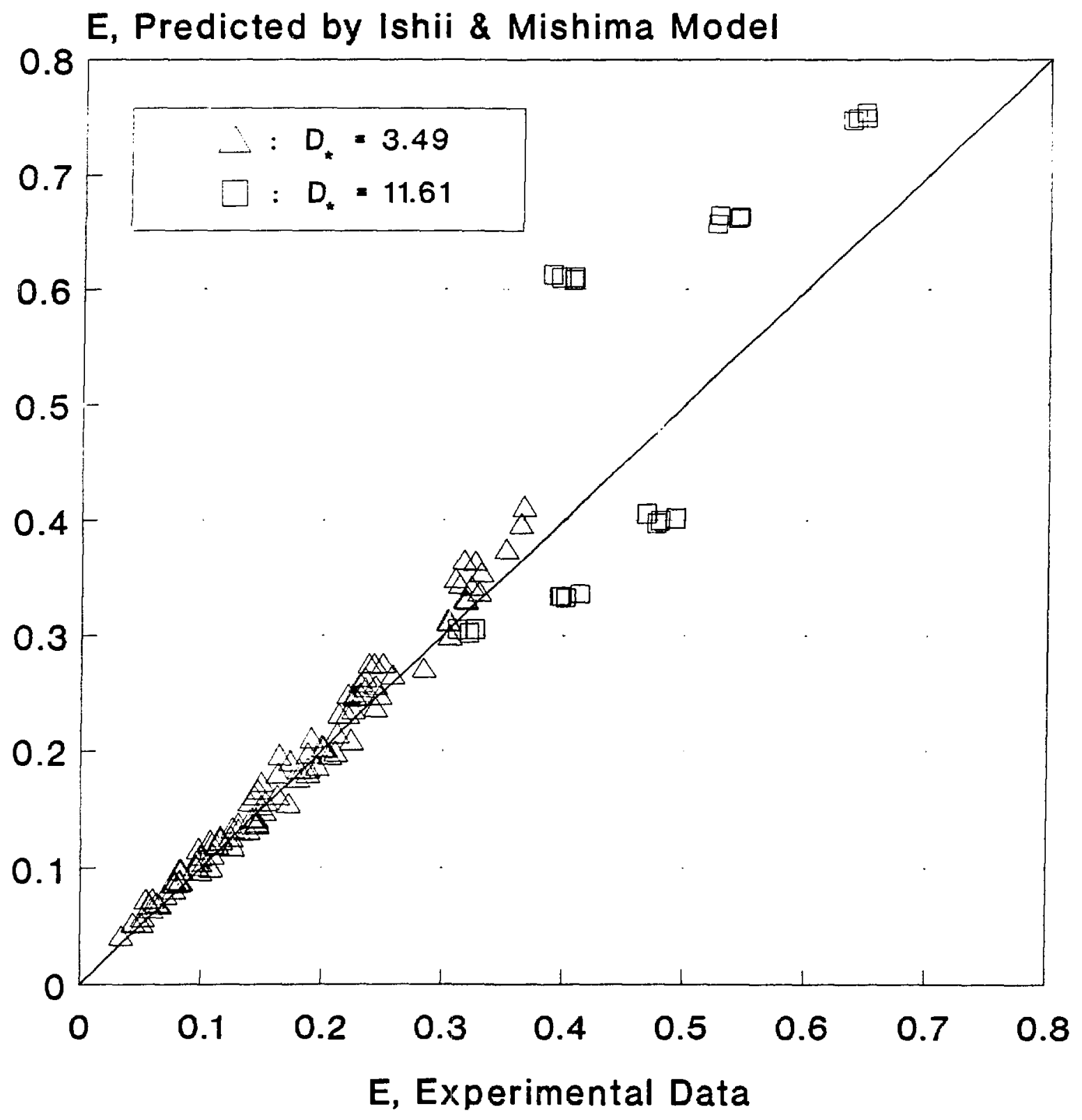

Figure 5. Predictions for the equilibrium entrainment fraction $\left(E_{\infty}\right)$ from the Ishii \& Mishima model, Equation (10), plotted against the experimental data of Cousins and Hewitt [15]. 


$$
\delta=\frac{D_{c}}{4}\left[\frac{d_{0}}{D_{c}}\right]^{0.5}
$$

The remaining geometrical parameters for this ID equivalent duct are then calculated as indicated in Section 2.2. The initial volume of melt in the cavity, $\mathrm{Vm}(0)$ is known. Let $\mathrm{Vm}(\mathrm{t})$ be the volume of melt within the cavity at any time $t$. Then, it follows that:

$$
V m(t)=V m(0)-\int_{0}^{t} A_{\min } E j_{f} d t
$$

where $A_{\min }$ is the minimurn of the two areas: $A, e$, the actual cavity exit area, and $P \delta$, the crosssectional area of the equivalent ID duct. This definition of the flow area through which the molten droplets are ejected out of the cavity is necessary for consistency with the physical model described in Section 2.2. Since the equivalent cavity has an area of cross-section equal to Po, this is the maximum area through which melt can flow out of the cavity. Furthermore, Equation (18) assumes that before the melt can be ejected out of the cavity, it must be first entrained as droplets. While this is certainly true for the Surry cavity model shown in Figure 2, it may not be true for all the cavities. For example, for the Zion cavity where the cavity exit comes down all the way to the floor of the cavity, and makes only an acute angle with the flow direction, melt film would be ejected from the cavity directly.

In order to calculate $\mathrm{Vm}$ from Equation (18), the unknowns $\mathrm{E}$ and $\mathrm{j}_{\mathrm{f}}$ must be calculated as a function of time. To calculate $j_{f}$ we use Equation (9), and to calculate $E$ we use Equation (13) with $C=4.6$, that is:

$$
E=\tanh \left[4.6 K u_{g}^{2} K u_{f}^{0.33}\left(\frac{\rho_{g}}{\Delta \rho}\right)^{1.4} D_{*}^{0.48}\left(1-\exp \left(-D_{*} / 8\right)\right)\right]
$$

The above value of $\mathrm{C}$ was chosen so as to yield good agreement between the experimental data for the fraction of melt dispersed from the reactor cavity model and the predictions from the transient model. This is further discussed in Section 4 . Next, the remaining unknown $\mathrm{j}_{\mathrm{g}}$, which appears in Equations (9) and (19), must be calculated. To do so, we must consider the transient blowdown of the gas from the pressure vessel.

Let $\mathrm{V}_{0}$ be the volume of the pressure vessel and $d_{0}$ be the diameter of the orifice in the pressure vessel bottom through which the gas is discharged into the reactor cavity (or cavity model). Since, for most cases of practical interest the initial pressure ${ }^{2}$ in the pressure vessel, $P_{0}$ is more than twice the pressure in the cavity, we shall assume that flow through the orifice

${ }^{2}$ The pressure in the vessel at the instant the gas blowdown starts. This instant corresponds to $\mathrm{t}=0$. 
is choked. Furthermore, we also assume that the flow through the orifice, and the expansion of gas in the pressure vessel, is isentropic. Then, it can be easily shown that $\mathrm{m}_{\mathrm{g}}(\mathrm{t})$, the mass flow rate of gas at any time $t$ through the orifice in the pressure vessel is given by:

$$
m_{g}(t)=m_{g}^{0}\left[1+\frac{(\gamma-1)}{2} \frac{m_{g}^{0}}{M_{0}} t\right]^{\frac{\gamma+1}{1-\gamma}}
$$

where $y$ is the specific heat ratio for the gas, and

$$
\begin{gathered}
m_{g}^{0}=C_{D}\left(\frac{\pi d_{0}^{2}}{4}\right) \sqrt{\gamma}\left(\frac{2}{\gamma+1}\right)^{\frac{\gamma+1}{2(\gamma-1)}} \frac{P_{0}}{\sqrt{R T_{0}}} \\
M_{0}=\frac{P_{0} V_{0}}{R T_{0}}
\end{gathered}
$$

$T_{0}$ is the initial temperature of the gas in the pressure vessel, $R$ is the particular gas constant for the gas, and $C_{D}$ is the discharge coefficient for sonic flow through an orifice. Based upon the experimental data presented in Reference [16], we have used a value of 0.74 for $C_{D}$. Since the mass flow rate of gas through the orifice can now be calculated using Equations (20), (21), and (22), the gas superficial velocity, $\mathrm{j}_{\mathrm{g}}$, in the $1 \mathrm{D}$ equivalent duct is easily calculated as:

$$
j_{g}(t)=\frac{m_{g}(t)}{A \rho_{g}}
$$




\section{MELT DISPERSAL PREDICTIONS FOR THE SURRY CAVITY}

\subsection{Comparison of Predictions and Experimental Data from $1 / 42^{\text {nd }}$ scale Experiments}

As discussed in Section 1.2, Tutu et al $[3,6,7]$ have performed a large number of melt dispersal experiments using small scale models of reactor cavities. These experiments yielded the data for $f_{\text {end }}$, the fraction of melt simulant that is retained in the cavity model at the end of the gas blowdown from the pressure vessel. If $t_{e n d}$ is the time to the end of the gas blowdown and $f(t)$ is the fraction of melt retained within the cavity at any time $t$, then:

$$
\begin{aligned}
& f(t)=\frac{V m(t)}{\operatorname{Vm}(0)} \\
& f_{\text {end }}=f\left(t_{\text {end }}\right)
\end{aligned}
$$

Since Vm(t) can be calculated using the model described in Section $2, \mathrm{f}_{\text {end }}$ can be calculated and compared with the experimental data. In this section we shall compare the predictions for $f_{\text {end }}$ with the experimental data for the Surry cavity model[7].

Figure 6 shows $f_{\text {end }}$ plotted against the initial vessel pressure $P_{0}$, for a series of experiments performed with water as the melt simulant and nitrogen as the blowdown gas. The diameter of the orifice in the pressure vessel bottom for these experiments was equal to 9.525 $\mathrm{mm}$. The small squares with interconnected lines represent the experimental data and the large squares represent the model predictions. Since the error in the measured values of $f_{\text {end }}$ was less than $\pm 3 \%$, the apparently rather large scatter in the experimental data is evidence of the chaotic nature of the melt dispersal process from the Surry cavity. As can be seen, excluding the rather long tail for large values of $P_{0}$, for which most of the melt is dispersed from the cavity in any case, the agreement between the data and predictions is quite good.

Figure 7 shows the data and predictions for another series of experiments for which the orifice size was smaller. As can be seen, the agreement is reasonable. Finally, the results for experiments which used helium as the blowdown gas are presented in Figure 8, and the results for experiments which used molten Wood's metal as the blowdown gas are shown in Figure 9. It should be noted that the same model with the same value of $C=4.5$, has been used to make all these predictions. Considering the rather complex nature of the melt dispersal process, and the fact that the aspect ratio ${ }^{3}$ of the cavity is not very large, it is remarkable that the highiy idealized quasi-equilibrium model is rble to predict, approximately, the experimental data for a large number of cases, reasonably well.

Although, no measurements of the fraction of melt dispersed from the cavity model as a function of time during the blowdown process have been performed to date, in Figure 10 we

${ }^{3}$ Length to hydraulic diameter ratio 
BNL DATA AND PREDICTIONS FROM MODEL

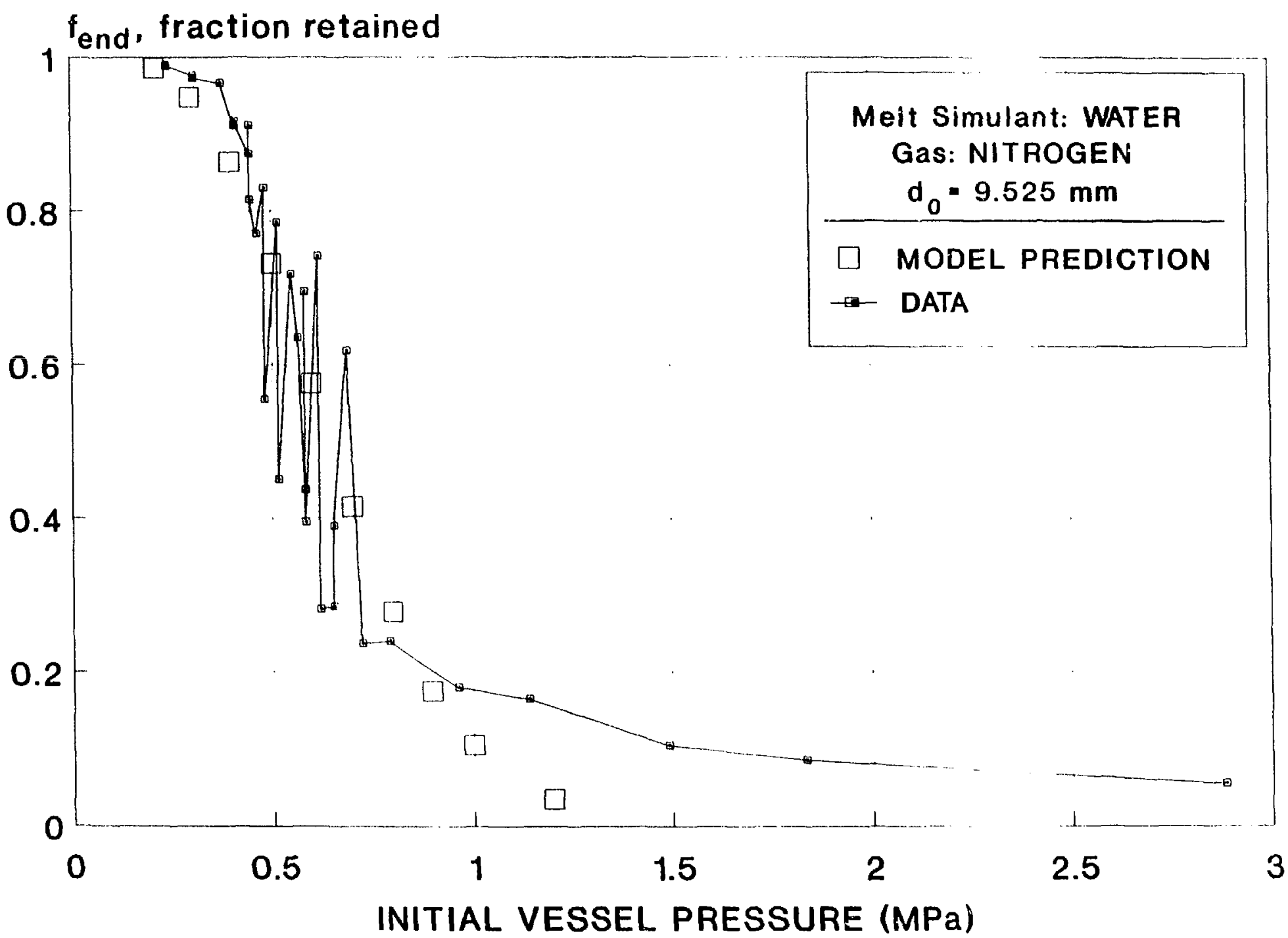

Figure 6. Predictions from the present nodel, and the experimental data of Tutu et al [7], for the fraction of melt retained within the Surry cavity model at the end of the gas blowdown $\left(f_{\text {end }}\right) . \quad V m(0)=1.903 \times 10^{4} \mathrm{~m}^{3}$ 


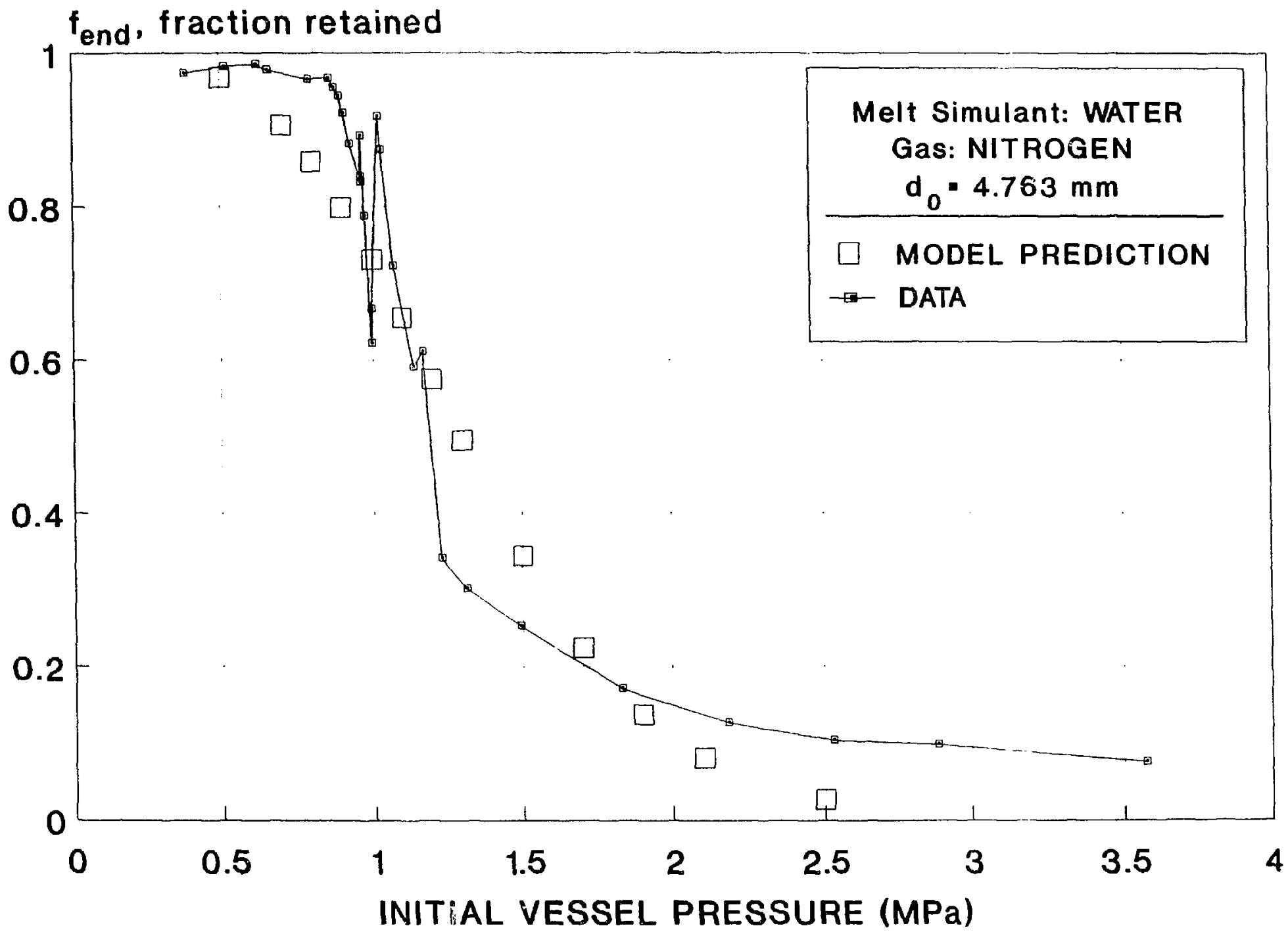

Figure 7. Predictions from the present model, and the experimental data of Tutu et al [7], for the fraction of melt retained within the Surry cavity model at the end of the gas blowdown $\left(f_{\text {end }}\right) . \operatorname{Vm}(0)=1.903 \times 10^{-4} \mathrm{~m}^{3}$ 
BNL DATA AND PREDICTIONS FROM MODEL

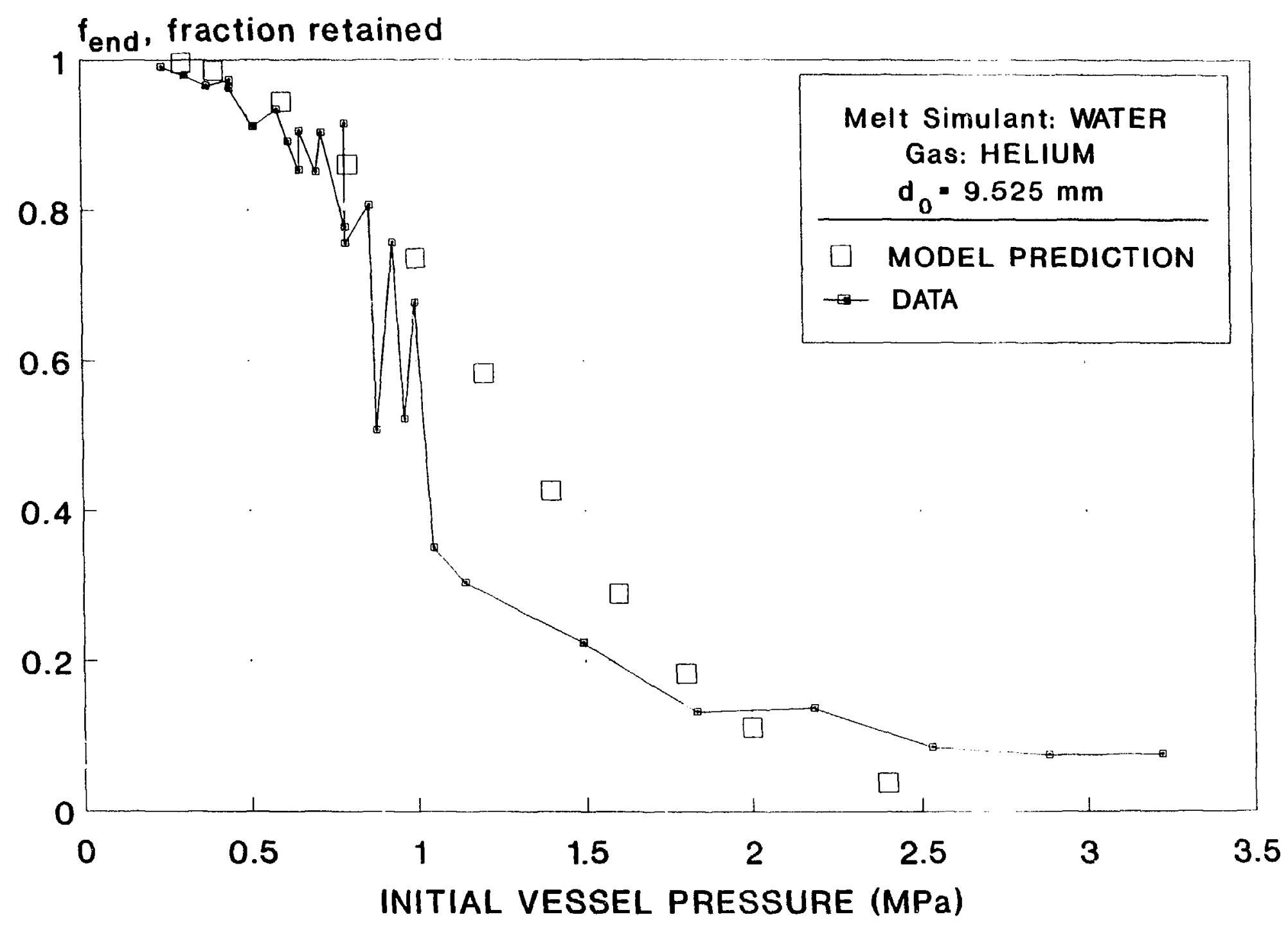

Figure 8. Predictions from the present model, and the experimental data of Tutu et al [7], for the fraction of melt retained within the Surry cavity model at the end of the gas blowdown $\left(f_{\text {end }}\right) . V m(0)=1.903 \times 10^{-4} \mathrm{~m}^{3}$ 
BNL DATA AND PREDICTIONS FROM MODEL

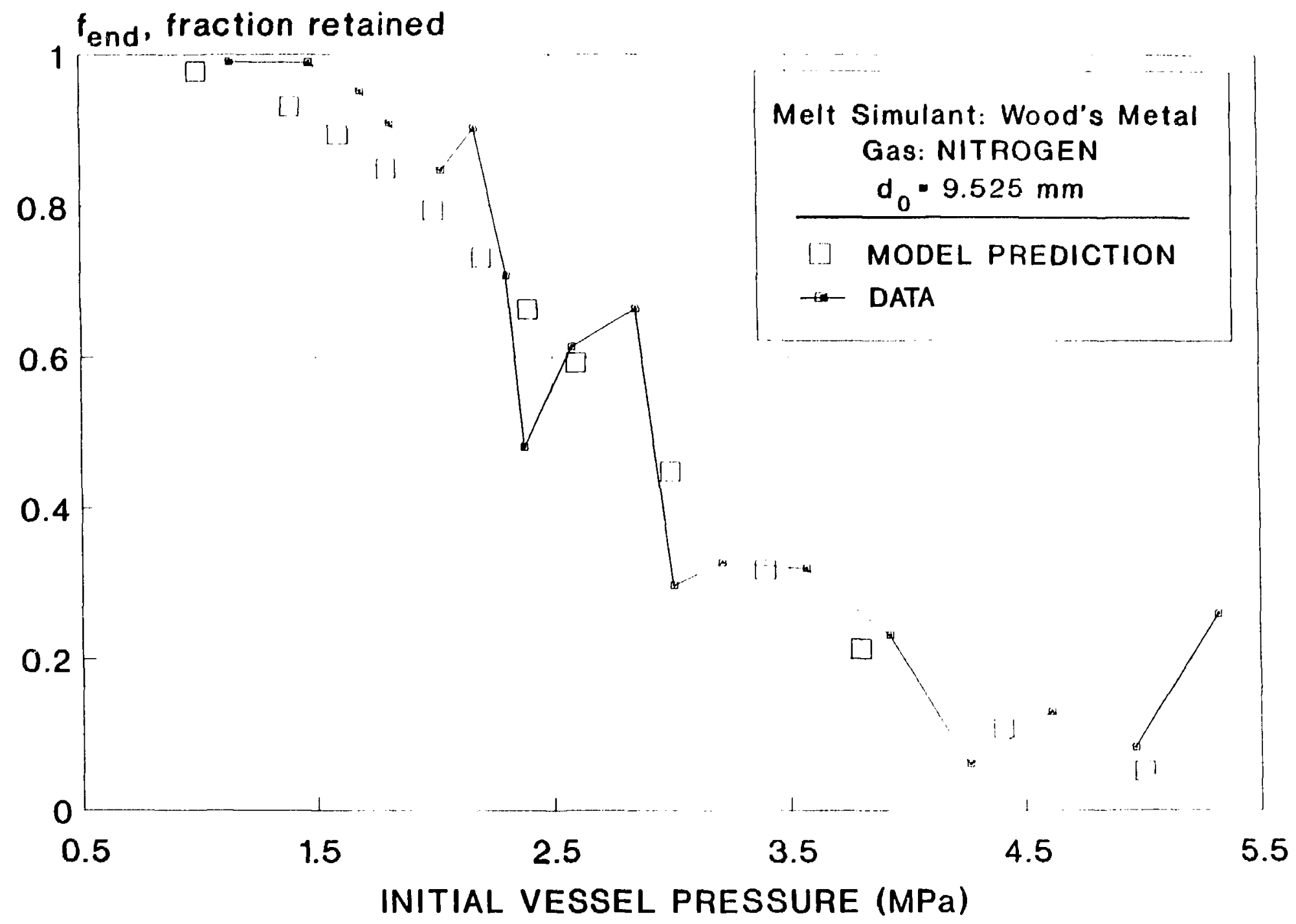

Figure 9. Predictions from the present model, and the experimental data of Tutu et al [7], for the fraction of melt retained within the Surry cavity model at the end of the gas blowdown $\left(f_{\text {cut }}\right) . V m(0)=1.882 \times 10^{4} \mathrm{~m}^{3}$ 


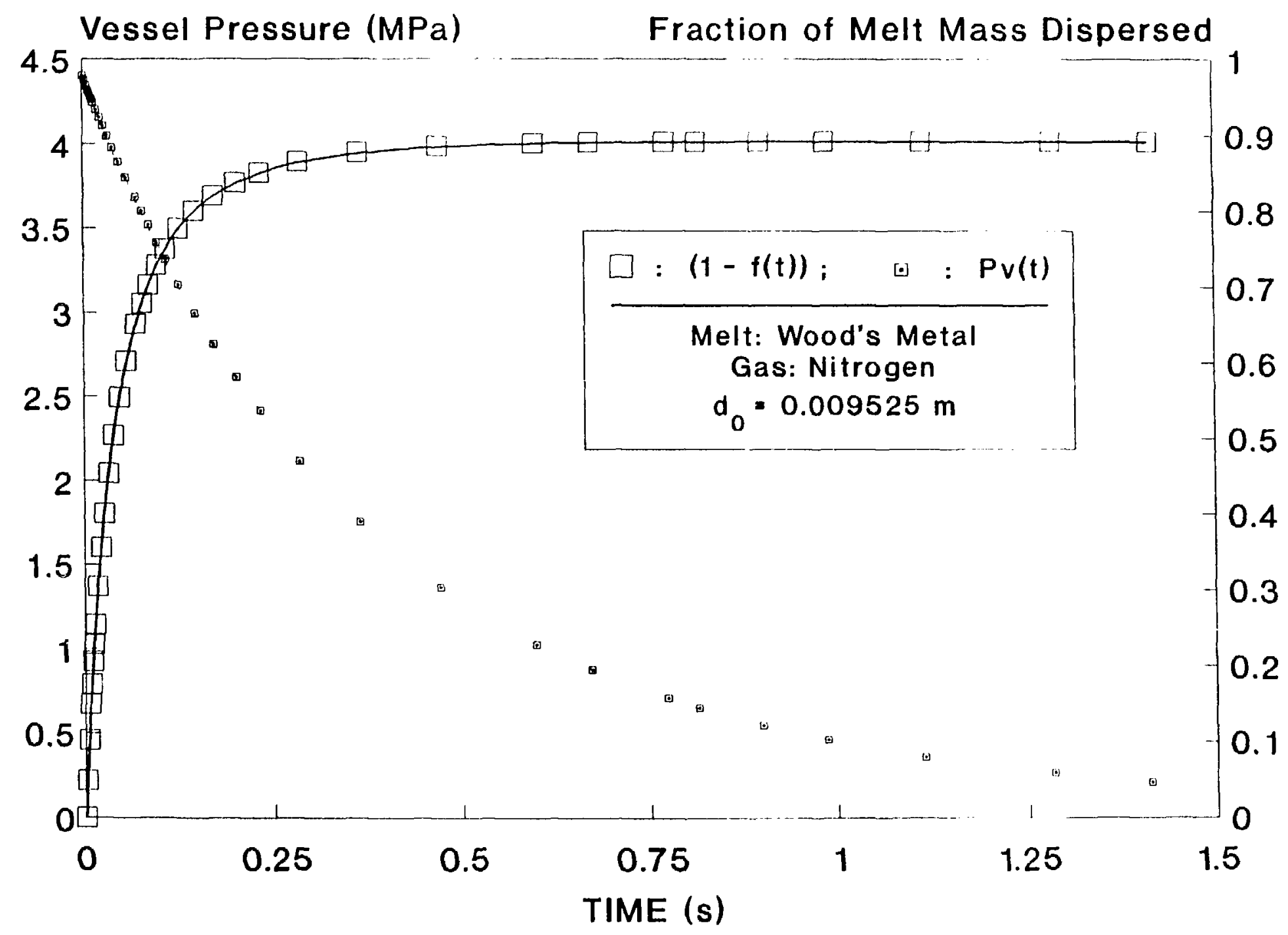

Figure 10. Predictions of the vessel pressure $\operatorname{Pv}(t)$, and the fraction of melt dispersed from the $1 / 42^{\text {mu }}$ scale Surry cavity model in the time interval zero to $t$, as a function of time. $P_{0}=\operatorname{Pv}(0)=4.4 \mathrm{MPa}$. 
show transient predictions for one hypothetical experiment. The initial pressure in the vessel, $\mathrm{P}_{0}$, for this case was $4.4 \mathrm{MPa}$. The curve with the small squares represents the pressure in the pressure vessel, $\operatorname{Pv}(t)$, as a function of time, and the curve with the large open squares shows the fraction of melt dispersed during the time interval zero to $t$. Note that $f(t)$ is the fraction of initial melt volume that is within the cavity at any time $t$. This figure indicates that although melt continues to be ejected from the cavity model during the blowdown process, the major fraction of the melt that is eventually ejected, is dispersed from the cavity in a duration that is much shorter than the vessel blowdown time.

\subsection{Predictions for the Full Scale Surry Cavity}

In this section, for purposes of demonstration, we shall present melt dispersal predictions for some hypothetical cases for the full scale Surry cavity. The model, as presented in Section 2 , is purely hydrodynamic in nature, and does not include melt-steam heat transfer. However, in the full scale accident scenario, since the molten core melt is much hotter than the steam flowing through the cavity, the steam temperature is likely to rise. Since the density of the gas flowing through the cavity is dependent upon its temperature, we shall here treat $\mathrm{T}_{0}$, the gas temperature in the cavity, as a parameter. As discussed in Section 1.2, Tutu et al $[3,6,7]$ have performed a scaling analysis of the melt dispersal process and developed dimensionless correlations for $f_{\text {end }}$ for each of the cavities studied. As shown in Reference [3], these correlations can be used to make predictions for $f_{\text {end }}$ for the full scale cavity. The details of this correlational analysis are beyond the scope of this paper, and the reader is referred to References $[3,6,7]$ for the details. Here, we shall merely display a comparison of the predictions for $f_{\text {end }}$ obtained from the present idealized model with those that were obtained from the direct use of the empirically based dimensionless correlation for $f_{\text {end }}$.

Figure 11 shows the predictions for the case when the diameter of the hole in the pressure vessel bottom is assumed to be $0.2 \mathrm{~m}$, and when the steam temperature within the cavity is assumed to be equal to $1500 \mathrm{~K}$. A similar comparison for the case when the hole diameter is assumed to be $0.5 \mathrm{~m}$, is shown in Figure 12. As can be seen, the agreement between the two predictions is reasonable.

As discussed in Section 1.1, in order to calculate the containment pressure loading due to $\mathrm{DCH}$, one must specify the rate at which the melt is ejected from the cavity. Therefore, for illustrative purposes, we shall next present some transient results for a few hypothetical full scale cases. In Figures 13 and 14 we present the results for two cases for which the hole diameter in the pressure vessel bottom is assumed to be $0.2 \mathrm{~m}$, and for which we have assumed the steam temperature within the cavity to be $1500 \mathrm{~K}$. These figures show calculated values for the vessel pressure as a function of time, and the fraction of melt ejected from the Surry cavity during the time interval zero to $t$ as a function of time. In Figure 13 we show the results for the case when $\mathrm{P}_{0}=7.5 \mathrm{MPa}$, and in Figure 14 we show the results for the case when $\mathrm{P}_{0}=4 \mathrm{MPa}$. Finally in Figure 15 we show similar predictions for one case which assumes the vessel hole diameter to be $0.5 \mathrm{~m}$. In all of these cases, it appears that the melt dispersal time, that is, the time during which most of the melt is dispersed from the cavity, is much shorter than the gas blowdown time from the pressure vessel. This is encouraging from the point of view of potential DCH loading, 


\section{RESULTS FOR FULL SCALE SURRY CAVITY}

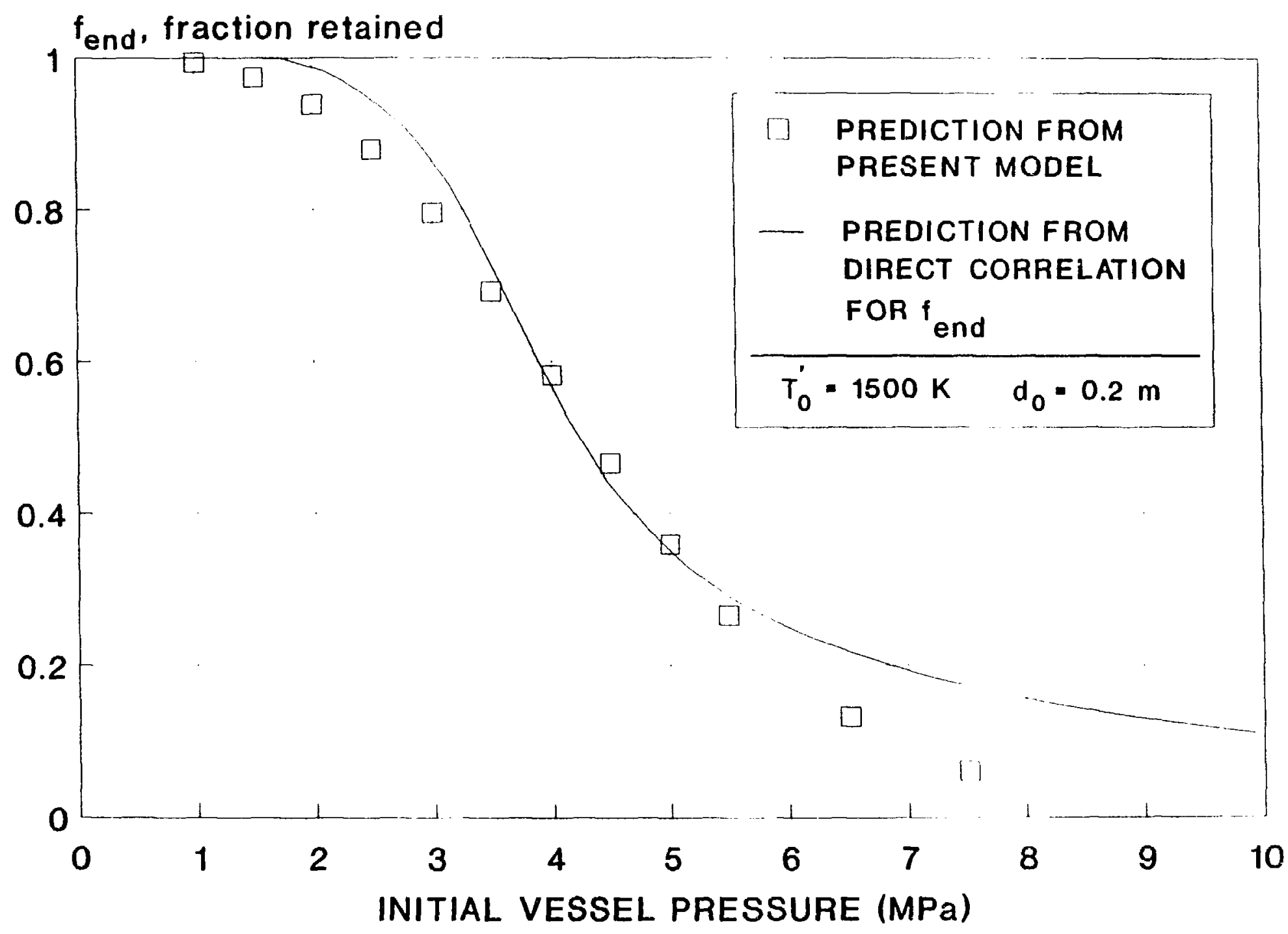

Figure 11. Comparison of predictions for $f_{\text {sad }}$ obtained from the present model, and those obtained from the empirical dimensionless correlation developed by Tutu et al [7], for the full scale Surry cavity. $V m(0)=14.0 \mathrm{~m}^{3}$. 


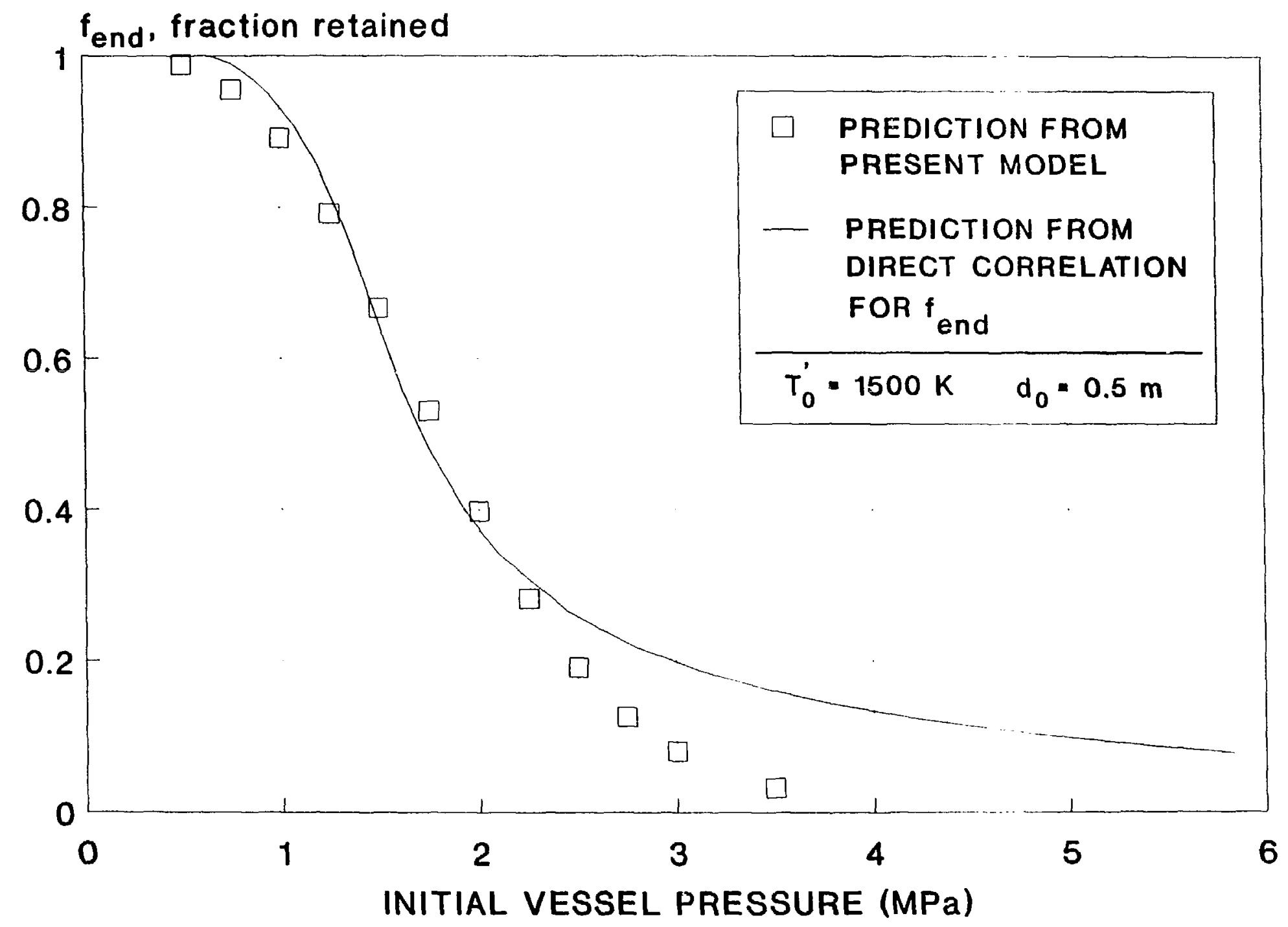

Figure 12. Comparison of predictions for $\mathrm{f}_{\mathrm{cud}}$ obtained from the present model, and those obtained from the empirical dimensionless correlation developed by Tutu et al [7], for the full scale Surry cavity. $V m(0)=14.0 \mathrm{~m}^{3}$. 


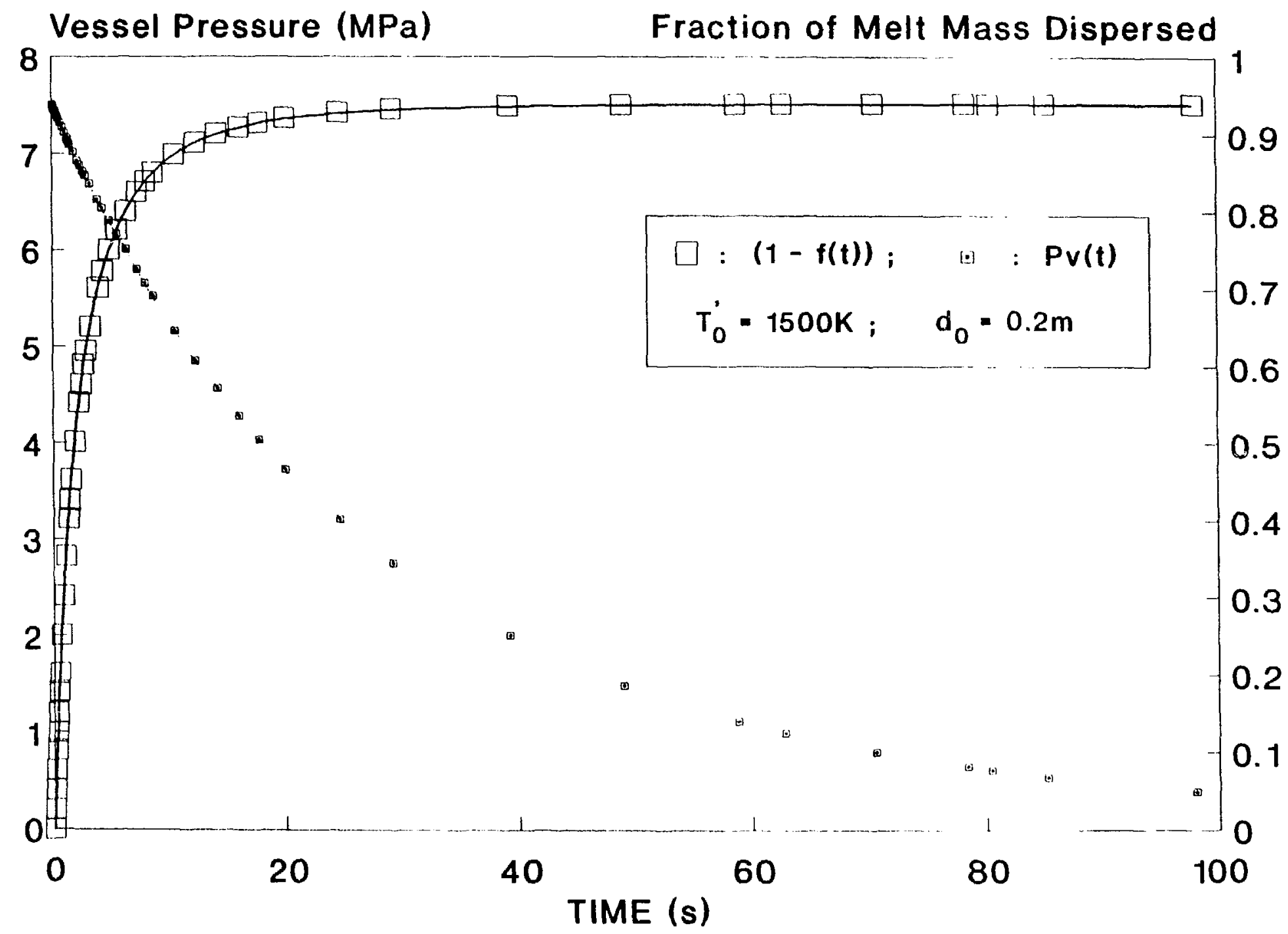

Figure 13. Predictions of the vessel pressure $P v(1)$, and the fraction of melt dispersed from the full scale Surry cavity in the time interval zero to $t$, as a function of time. $P_{0}=P v(0)=7.5 \mathrm{MPa}$. 


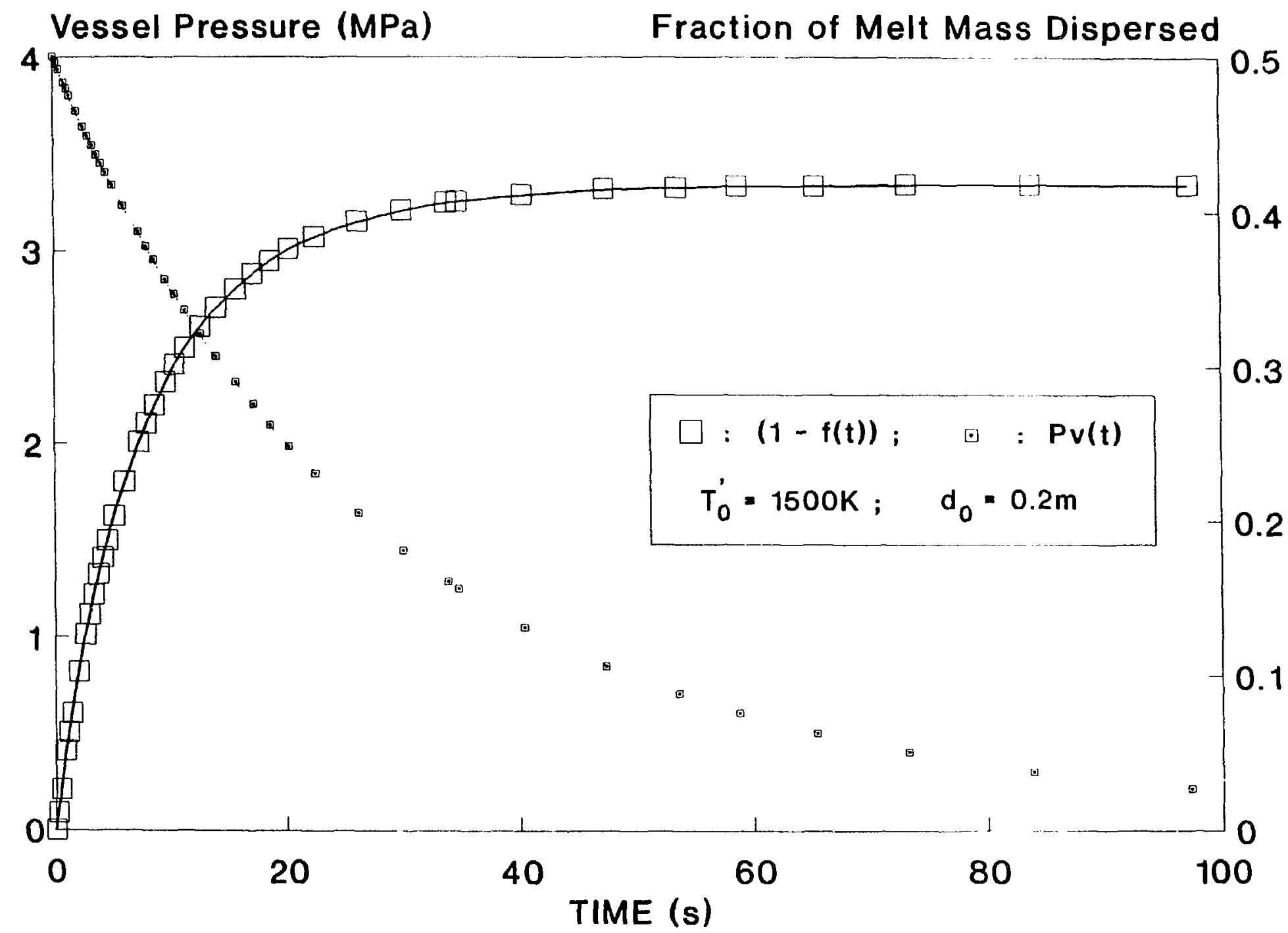

Figure 14. Predictions of the vessel pressure $P v(t)$, and the fraction of melt dispersed from the full scale Surry cavity in the time interval zero to $\mathrm{t}$, as a function of time. $\mathrm{P}_{0}=\mathrm{Pv}(0)=4.0 \mathrm{MPa}$. 


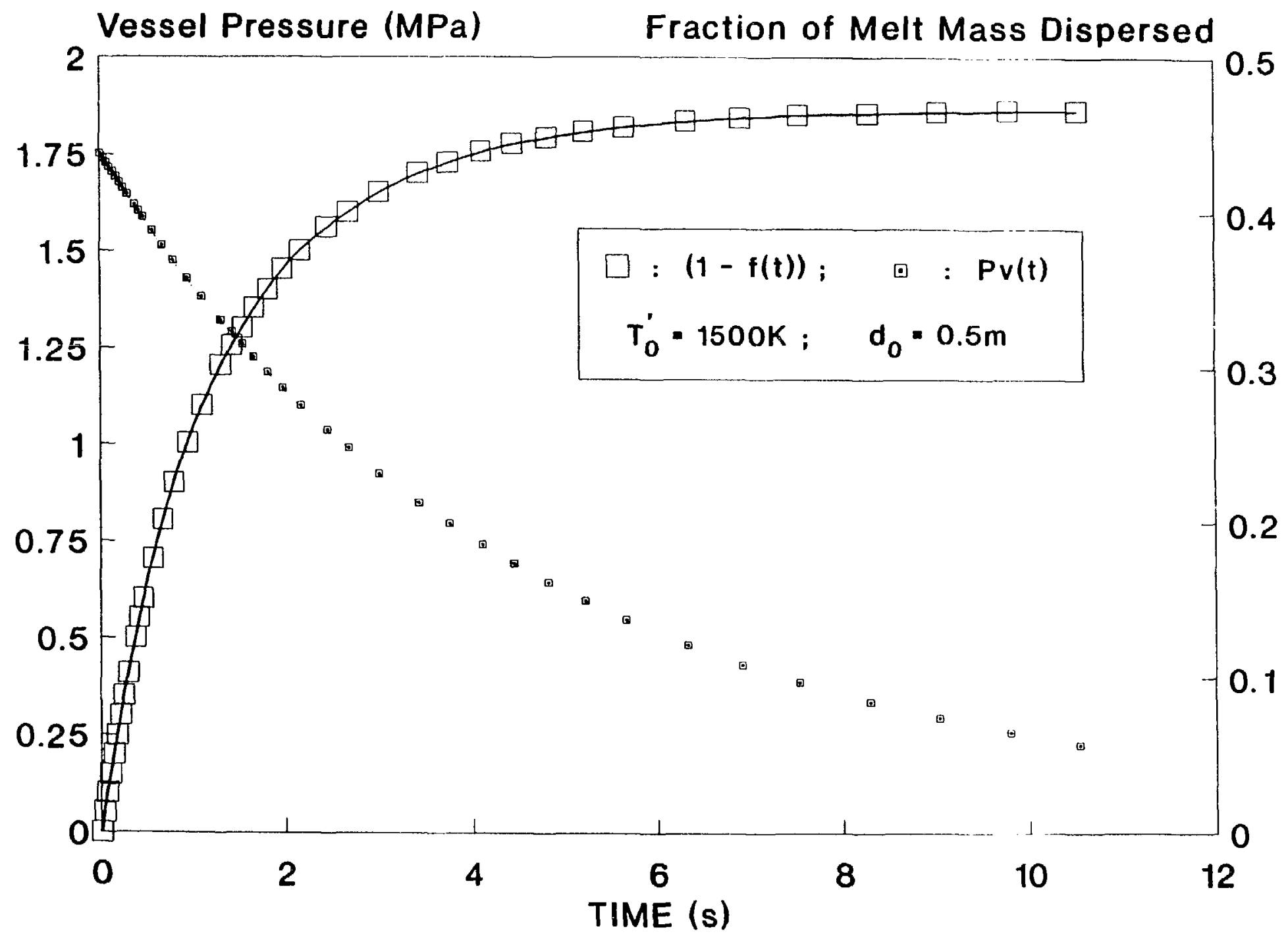

Figure 15. Predictions of the vessel pressure $\operatorname{Pv}(t)$, and the fraction of melt dispersed from the full scale Surry cavity in the time interval zero to $t$, as a function of time. $P_{0}=\operatorname{Pv}(0)=1.75 \mathrm{MPa}$. 
because this implies that the extent of steam-melt chemical reaction, and hence hydrogen production within the cavity may be limited by the availability of steam [17]. It is emphasized that these full scale predictions are provided for illustrative purposes only, and since these obviously depend upon the initial conditions assumed, in order to use such predictions for DCH loading calculations, these calculations should be re-performed with the appropriate initial conditions. Furthermore, the value of the constant $C$ in Equation (13), which for the Surry cavity was found to be equal to 4.6 , is likely to be different for a cavity whose shape is very different from the Surry cavity. 


\section{CONCLUDING REMARKS}

An idealized and simple model to predict the transient melt dispersal rate from reactor cavities during pressurized melt ejection accident scenarios has been developed. The model assumes the flow of melt film, molten droplets, and the gas to be in a state of quasi-equilibrium during the blowdown process. Furthermore, the model uses a correlation for $E_{\infty}$, the equilibrium value for the fraction of liquid flux flowing as droplets in an annular one dimensional gas liquid flow. This correlation for $\mathrm{E}_{\infty}$ was developed by modifying the Ishii and Mishima [14] correlation. The value of the constant $C$ appearing in this correlation ( Equation (13) ) that was found to give the best agreement with the experimental data of Cousins and Hewitt [15] for annular flow of air and water in very long vertical tubes was equal to 8.64. The results presented here show that using $C=4.6$, which is less than a factor of two different from the value of 8.6 quoted above, results in reasonably good agreement with the melt dispersal data obtained from a large number of experiments with the small scale Surry cavity model. This experimental data base included the melt simulant (molten Wood's metal or water) and the blowdown gas (nitrogen or water) as parameters. Let $\mathrm{x}$ be the axial distance along a pipe of diameter D, then, as demonstrated by Ishii \& Mishima [14] and Cousins \& Hewittt [15], very large values of $x / D$ are required before $E(x)$ reaches its equilibrium value of $E_{\infty}$. As shown by Ishii and Mishima [14], the value of $E$ in the entrance region of a pipe can easily be lower than an order of magnitude from the equilibrium value $E_{\infty}$. In view of this, and the facts that the aspect ratio (effective $x / D$ ) of the Surry cavity is rather small, and that the value of the constant $C$ needed to give good agreement with the experimental data for the Surry cavity model differs by less than a factor of two from the value needed for steady annular flow in very long pipes, the results obtained using this model are very encouraging.

The simple model described here, provides a methodology to calculate a first approximation to the transient melt dispersal rate from reactor cavities during pressurized melt ejection accident scenarios. The results of these calculations can then be used to perform more realistic CONTAIN-DCH calculations. 


\section{REFERENCES}

1. Pilch M. and W. W. Tarbell (1985), "High Pressure Ejection of Melt From a Reactor Pressure Vessel. The Discharge Phase," NUREG/CR-4383, SAND85-0012.

2. Ginsberg, T. and N. K. Tutu (1988), "Progress in Understanding of Direct Containment Heating Phenomena in Pressurized Light Water Reactors," Proceedings of Third International Topical Meeting on Nuclear Power Plant Thermal Hydraulics and Operations, Seoul, Korea (November 1988).

3. Tutu, N. K. et al. (1990), "Melt Dispersal Characteristics of the Watts Bar Cavity," Technical Report \# A-3024, 4/90, Brookhaven National Laboratory, Dept. of Nuclear Energy, Upton, NY 11973.

4. Bergeron, K. D. and D. C. Williams (1985), "CONTAIN calculations of Containment Loading of Dry PWRs," Nucl. Eng. \& Des., 90, pp 153-159.

5. Tutu, N. K. et al. (1991), "Estimation of Containment Pressure Loading Due to Direct Containment Heating for the Zion Plant," NUREG/CR-5282, BNL-NUREG-52181.

6. Tutu, N. K. et al. (1988), "Debris Dispersal From Reactor Cavities During HighPressure Melt Ejection Accident Scenarios," NUREG/CR-5146, BNL-NUREG-52147.

7. Tutu, N. K. and T. Ginsberg (1990), "A Letter Report on the Results of Melt Dispersal Experiments with the Surry and Zion Cavity Models," submitted to USNRC, Oct. 1990, Department of Nuclear Energy, Brookhaven National Laboratory, Upton, NY 11973.

8. Spencer, B. W. et al. (1982), "Sweepout Thresholds in Reactor Cavity Interactions," Argonne National Laboratory Report \# ANL/LWR/SAF 82-1, Argonne, IL 60439.

9. Spencer, B. W., D. Kilsdonk, and J. J. Sienicki, "Hydrodynamics Aspects of Ex-vessel Debris Dispersal in Zion-type Containment Design, Argonne National Laboratory Report \# ANL/LWR/SAF 83-1, Argonne, IL 60439.

10. Tarbell, W. W., et al. (1986), "Pressurized Melt Ejection Into Scaled Reactor Cavities," NUREG/CR-4512, SAND86-0153.

11. Tarbell, W. W. (1988), "Debris Dispersal Threshold for Pressurized Melt Ejection Accident Sequences," presented at USNRC Severe Accident Research Program Partners Review Meeting, Albuquerque, NM (April, 1988).

12. Macbeth, R. V. and R. Trenberth (1987), "Experimental Modelling of Core Debris Dispersion from the Vault Under a PWR Pressure Vessel," AEEW-R 1888, WINFRITH, United Kingdom Atomic Energy Authority. 
13. Hall, J. A. and J. T. Dawson (1991), "Overview of United Kingdom Experiments on High Pressure Melt Ejection," Nuclear Electric, Berkely Nuclear Laboratories, UK, Presented at USNRC Cooperative Severe Accident Research Program Review Meeting, Bethesda, Maryland (May 1991).

14. Ishii, M. and K. Mishima (1989), "Droplet Entrainment Correlation in Annular TwoPhase Flow," Int. J. Heat Mass Transfer, Vol. 32, No 10, pp 1835-1846.

15. Cousins, L. B. and G. F. Hewitt (1968), "Liquid Phase Mass Transfer in Annular TwoPhase Flow: Droplet Deposition and Liquid Entrainment," Experimental data from Tables 1 and 2, UK Atomic Energy Authority Report AERE - R 5657.

16. Shapiro, A. H. (1953), "The dynamics and Thermodynamics of Compressible Flow" Volume 1, p359, John Wiley \& Sons.

17. Tutu, N. K. and T. Ginsberg (1987), "Parametric Calculations of Hydrogen Generation in the Zion Reactor Cavity Region," Thermal-Hydraulic Reactor Safety Experiments, Chapter 10, Safety Research Programs sponsered by the Office of Nuclear Regulatory Research, compiled by Allen J, Weiss, NUREG/CR-2331, BNL-NUREG-51454, Vol. 7, Nos. $2 \& 3$. 